NBER WORKING PAPER SERIES

\title{
EXPLORING TRADEOFFS IN THE ORGANIZATION OF SCIENTIFIC WORK: COLLABORATION AND SCIENTIFIC REWARD
}

\author{
Michaël Bikard \\ Fiona E. Murray \\ Joshua Gans \\ Working Paper 18958 \\ http://www.nber.org/papers/w18958 \\ NATIONAL BUREAU OF ECONOMIC RESEARCH \\ 1050 Massachusetts Avenue \\ Cambridge, MA 02138 \\ April 2013
}

This paper was originally distributed with the title, "Is Collaboration Creative or Costly?" We thank Lotte Bailyn, Emilio Castilla, Michael Cusumano, Roberto Fernandez, Benjamin Jones, Ray Reagans, Edward Roberts, Henry Sauermann, Scott Stern, James Utterback, Ezra Zuckerman, seminar participants at the Darden Entrepreneurship and Innovation Research Conference, the Academy of Management Annual Conference, MIT Sloan Innovation and Entrepreneurship Seminar and Economic Sociology Working Group, as well as other conferences and seminars. Financial support from the Ewing Marion Kauffman Foundation, MIT Energy Initiative and the Roberts E-Center Fund is gratefully acknowledged. Financial support from the Toulouse Network on Information Technology is gratefully acknowledged. Gans consults for Microsoft but it is not related this this research. All errors are our own. The views expressed herein are those of the authors and do not necessarily reflect the views of the National Bureau of Economic Research.

NBER working papers are circulated for discussion and comment purposes. They have not been peerreviewed or been subject to the review by the NBER Board of Directors that accompanies official NBER publications.

(C) 2013 by Michaël Bikard, Fiona E. Murray, and Joshua Gans. All rights reserved. Short sections of text, not to exceed two paragraphs, may be quoted without explicit permission provided that full credit, including $\left({ }^{\circ}\right.$ notice, is given to the source. 
Exploring Tradeoffs in the Organization of Scientific Work: Collaboration and Scientific Reward Michaël Bikard, Fiona E. Murray, and Joshua Gans

NBER Working Paper No. 18958

April 2013

JEL No. O31,O33

\begin{abstract}
$\underline{\text { ABSTRACT }}$
When do scientists and other knowledge workers organize into collaborative teams and why do they do so for some projects and not others? At the core of this important organizational choice is, we argue, a tradeoff between the productive efficiency of collaboration and the credit allocation that arises after the completion of collaborative work. In this paper, we explore this tradeoff by developing a model to structure our understanding of the factors shaping researcher collaborative choices in particular the implicit allocation of credit among participants in scientific projects. We then use the annual research activity of 661 faculty scientists at one institution over a 30-year period to explore the tradeoff between collaboration and reward at the individual faculty level and to infer critical parameters in the organization of scientific work.
\end{abstract}

Michaël Bikard

Ewing Marion Kauffman Foundation

mbikard@mit.edu

Fiona E. Murray

MIT Sloan School of Management

100 Main Street, e62-470

Cambridge, MA 02142

fmurray@mit.edu
Joshua Gans

Rotman School of Management

University of Toronto

105 St. George Street

Toronto ON M5S 3E6

and NBER

joshua.gans@gmail.com 


\section{INTRODUCTION}

In 2008, the Journal of Instrumentation published a paper entitled "The ATLAS Experiment at the CERN Large Hadron Collider" which documented the installation and expected performance of the ATLAS detector that had been installed as a critical component of the Large Hadron Collider to extend the frontiers of particle physics. As the paper states "This detector represents the work of a large collaboration of several thousand physicists, engineers, technicians, and students over a period of fifteen years of dedicated design, development, fabrication, and installation" (p.1). This crisply illustrates the changing nature of scientific work with the need for large numbers of individuals with distinctive expertise to work collaboratively in the solution of a complex scientific problem (Jones 2009). However, while the demands for new more expansive modes of organization push scientists towards larger collaborative groups the reward system for science has not necessarily changed as dramatically: The paper described above has over 1000 authors listed alphabetically, thus, raising the question of whether and how individual authors receive credit for their scholarly contributions. Posed more broadly, how should knowledge workers with high levels of organizational autonomy - such as academic scientists, computer programmers and independent inventors - organize their creative activities? How should they structure their collaborative choice in the light of the potential tradeoff between collaboration on the one hand and credit allocation on the other?

This question is of normative interest as autonomy becomes more prevalent among those engaged in the production of new knowledge, thus, allowing many more individuals to choose the degree to which they work collectively and in collaboration with others in the pursuit of creative outcomes. Not simply a question shaping the daily lives of academic scientists, this is also an issue of managerial import as complex tasks yield only to growing teams leaving open the question of how to allocate credit and other task-based incentives (Holmstrom, 1982; McAfee \& McMillan, 1991). The collaboration versus credit question is also of considerable theoretical interest to scholars in light of the increased collective organization of knowledge work inside organizations, in the Academy and in knowledge communities (see for example DiMaggio 2003; Cummings \& Kiesler 2007, Adler et al. 2008).

The rise in collective work, in general, and collaborative work, in particular, suggests that collaboration is a highly advantageous organizational choice, particularly for scientists (Wutchy et al. 2007). Empirical evidence repeatedly showing that the creative outputs accomplished by a larger number of people tend to be of higher quality particularly for scientists (Singh \& Fleming 2010; Wuchty et al. 2007) but also, for instance, in paintings (Hargadon 2008) and theatre (Uzzi and Spiro 2005). These "facts

on the ground" are also greeted with great optimism among scholars who enthusiastically describe the emergence of a "new norm" of collectiveness replacing the age-old tradition of the individual genius (Beaver 2001; Wray 2002; Johansson 2004). Certainly, many studies highlight collaboration's positive 
aspects: the ability to tap into diverse sources of knowledge (Fleming et al. 2007), the potential to democratize knowledge production (Von Hippel 2005), and its critical role in greater levels of creativity (Hargadon 2003).

Should we, therefore, assume that collaboration is the most effective way to organize knowledge work? Or are there hidden or unmeasured costs associated with the collaborative organization of knowledge production? Scholars in social psychology have provided a more nuanced perspective on the costs of collaboration on creativity (Paulus \& Nijstad 2003). Others taking an efficiency perspective (see for example recent analysis by Lee and Bozeman 2005) note that "a trivial but obvious cost [of collaboration], only one person can talk at a time during meetings - assumedly, such communication is instantaneous and almost costless within an individual" (Singh and Fleming (2010, p. 53). A further cost borne by the individual scientist relates to the allocation of credit. Particularly within the scientific community, the central reward system for scientific work is grounded in the provision of credit in reward for novel contributions to the knowledge base (see Dasgupta and David 1994). Traditional modes of credit allocation have been grounded in manuscript authorship and citations to a particular paper - a system that is particularly effective when knowledge work was a largely "solo" activity but is rendered much more complex as knowledge work (and with it authorship) expands to including growing numbers of individuals. Thus, for an individual scientist, the choice of collaboration is made in the shadow of possible tradeoffs in credit allocation as well as other efficiency considerations (Engers et.al., 1999; Gans and Murray, 2013). However, the current analysis of collaboration only in terms of output (i.e. the quality of papers produced) fails to evaluate tradeoffs at the individual level. Thus, the literature ignores whether the benefit to individuals of collectiveness are offset by high potential costs in terms of credit allocation (and other efficiency costs).

In this paper, we take an individual level perspective and evaluate the key tradeoff between the possible benefits of collaboration for the generation of specific outputs -in terms of quantity and quality and the costs of collaboration to individuals' overall productivity and credit allocation. To do so, we develop a theoretical model that focuses on the decision of an individual scientist in managing their portfolio of research activities building on the model of Becker and Murphy (1992) (that is unrelated to scientific work but highlights production choices). Our model makes three assumptions: that a scientist has a fixed time to allocate to all projects, has discretion in the mode of collaboration and is motivated not only by maximizing quality (citations) but maximizing citations allocated to them. While stylized in nature, these assumptions allow us to derive a set of predictions regarding collaborative behavior and credit allocation tradeoffs. We then test these assumptions by examining the academic publications of 661 faculty-scientists from one institution - the Massachusetts Institute of Technology - over a thirty year period from 1976 to 2006 . 
Our approach is narrower in scope than the massive data-based efforts analyzing millions of knowledge outputs (Newman 2001; Wuchty et al. 2007) but larger than qualitative small-scale investigations (Melin 2000; Hara et al. 2003). Nonetheless, an individual-level approach (to theoretical modeling and empirics) allows us to consider not only the output of collaboration but the net value of collaboration. It presents three crucial advantages over prior studies. First, we can make a realistic examination of the relationship between collaboration and credit at the scientist-year level. Second, we can control for individual's tendency to consistently take part to larger or smaller projects by adding individual-level fixed-effects. Third, we can control for the broader organizational environment by focusing on one institution (adding department-year level fixed-effects).

Our empirical results suggest that collaboration (among MIT researchers) is associated with more highly cited work on a per paper basis, and on an annual basis with more fractional credit - suggesting that credit allocation is not simply divided among the authors of a paper. A given individual in our sample can hope to see their papers receive on average over $60 \%$ more citations if they choose to collaborate with a coauthor as opposed to working alone. Up to 4 coauthors, collaboration is also associated with the publication of more papers per author. Using a revealed preference approach, our data also indicates that scientists might be disproportionately rewarded for more collaborative work-i.e. that credit for a given collaborative paper is shared across coauthors in a way that sums up to more than 1 . Not all collaborations are equal, however. In line with theories of cross-fertilization of ideas and division of labor, we find that cross-departmental collaborations tend to produce higher quality papers at a lower productivity cost than within-departmental work. Free-riding is also apparent: the quality gain is particularly low and the productivity loss is particularly high when collaborating with a more senior scientist, especially if that scientist is from the same department.

The paper is organized into five sections. In Section 2 we outline the tradeoffs between collaboration as an input into scientific work and credit sharing in the output of collaboration. Section 3 lays out a formal model of this tradeoff from which we derive clear hypotheses. Section 4 describes our setting and method. We detail our results in Section 5. We end with discussion and conclusions.

\section{COLLABORATION VERSUS CREDIT TRADEOFF}

Enthusiasm for collaboration is most visible among practitioners: A large number of popular press articles, books, and consulting business reports claim that collaboration provides a superior form of work organization (Hoerr 1989; Dumaine \& Gustke 1990; Katzenbach et al. 1993; Orsburn \& Moran 2000; Koplowitz et al. 2009). Similarly, in scientific research, the vast majority of policy-makers have embraced the trend toward larger research groups and supports its further development (J. S. Katz \& Martin 1997; Landry \& Amara 1998; Stokols et al. 2005). In the US, for instance, the National Institute of 
Health (NIH) Roadmap for Medical Research lists changing "academic culture to foster collaboration" as one of its four main objectives. ${ }^{1}$ Accordingly, it has made available a number of grants to support collective science. For example, the aptly named "Glue Grants" program ${ }^{2}$ from the National Institute of General Medical Sciences allocates tens of millions of Dollars to encourage scientists to collectively "tackle complex problems that are of central importance to biomedical science." Overall, the positive perception of collaboration in scientific research was crystallized in the Science editorial written by former National Science Board ${ }^{3}$ chairman arguing that: "It is clear that knowledge and distributed intelligence holds immense potential, both from a scientific standpoint and as a driver of progress and opportunity for all Americans" (Zare 1997).

Edward Lawler, in an interview for Fortune, takes a more nuanced view in line with our theoretical and empirical approach when he noted that “teams are the Ferraris of work design, they're high performance but high maintenance and expensive" (Dumaine 1994, p.2). This highlights the central tension between the positive benefits of collaboration and the possible negative tradeoffs for creative work. In laying out the tradeoffs, we focus on the benefits of collaboration (versus working alone) from a variety of theoretical perspectives and then contrast this with the costs including efficiency considerations but also more centrally the costs in terms of credit allocation.

\subsection{Collaboration's Benefits}

Researchers, like many practitioners, are traditionally optimistic about the impact of collaboration on creative work. At the core of this perspective lies the notion that the division of labor allows individuals endowed with different knowledge, beliefs, skills, and social networks to come together, thus enabling creativity and novelty. Accordingly, groups establish an ideal context for creativity through the recombination of existing ideas (Gilfillan 1935): the variety of ideas and contexts to which group members have been exposed can be easily united during collaborative work, potentially igniting an explosion of novel ideas - a phenomenon popularized as "the Medici Effect" (Johansson 2004). It has been argued that collaborative groups enhance the circulation of knowledge by bringing together members with different information, social networks, and skills (Cummings 2004; Singh 2005; Ding et al. 2010). They do so in part because individuals serve as brokers fostering inspiration across domains (Hargadon \& Sutton 1997; Obstfeld 2005; Fleming et al. 2007; Singh \& Fleming 2010; Girotra et al. 2010). More specifically, researchers have documented that social interactions can indeed lead to fleeting moments of collective creative insight (Hargadon \& Bechky 2006) and that collective work enables members to identify and filter out bad ideas before they fully develop (Singh \& Fleming 2010). In

\footnotetext{
${ }^{1}$ http://nihroadmap.nih.gov/

${ }^{2}$ http://www.nigms.nih.gov/Initiatives/Collaborative/GlueGrants/

${ }^{3}$ Governing body of NSF
} 
addition, groups can be safe arenas for individuals to express original ideas without fearing ridicule (Edmondson 1999). With regards scientific work, by bringing together individuals endowed with different types of knowledge (Porac et al. 2004; Hara et al. 2003), scholars argue that collaboration allows scientists to take advantage of specialization in the deep stock of scientific knowledge while at the same time gaining the benefits of breadth (Jones 2009).

Empirical evidence supports the view that collaboration leads to significant benefits on a variety of output dimensions: The commercial success of creative work such as comic books, Hollywood productions and Broadway musicals, as well as its reception by critics, has been linked to collaboration (Taylor \& Greve 2006; Cattani \& Ferriani 2008; Uzzi \& Spiro 2005). Survey data and field work in firms also highlight the positive performance of groups performing creative work compared to individuals (Obstfeld 2005; Burt 2004; Hargadon \& Bechky 2006). As noted in the introduction, more systematic quantitative evidence linking more creative tasks to larger groups is largely based on analyses of both scientific knowledge - patents and papers. Here, the data show that outputs authored by more scientists tend to receive more citations (Adams et al. 2005; Wuchty et al. 2007; Fleming 2007). For instance, Wuchty and colleagues (2007) studying 20 million scientific publications and over 2 millions patents find a clear and increasing advantage of collaborative work in all broad research areas. Specifically, Science and Engineering papers written by two authors received 1.30 more citations than sole-authored papers in the $1950 \mathrm{~s}$ and that this ratio increased to 1.74 by the $1990 \mathrm{~s}{ }^{4}$

Beyond assessing the average effect, collaboration is thought to impact the variance in creative outcomes. The direction of this relationship, however, is complex and current results are contradictory. On the one hand, Taylor and Greve (2006) find that collaboration in comic books increases the variance in good and bad outcomes. On the other, in an analysis of US utility patents, Fleming (2007) finds the opposite - i.e. individual inventors are the source of more failures and more breakthroughs. More recently, a careful study of the creative outcome distribution of over half million patents (as captured by their citations), using quartile regressions shows that collaboration reduces the probability of poor outcomes while increasing the probability of extremely successful ones (Singh and Fleming 2010).

\subsection{Tradeoffs - coordination and credit}

Research (as personal experience) suggests a number of potential coordination costs associated with collaboration. These costs consume time and have a variety of origins including conflicting goals and incentives, communication difficulties, the need for translation for or education of collaborators of different backgrounds and the need for processes and routines to distribute work, synchronize, and

\footnotetext{
${ }^{4}$ In their data, self-citations account for only $5-10 \%$ of the relative citation advantage of collaboration, therefore even accounting for self-citations "the relative citation advantage of teams remains essentially intact" (Wuchty et al. 2007, p.2)
} 
monitor progress. The issue of synchronization is perhaps most eloquently described by Leslie Perlow in her study of the organization of time at work among Ditto's software engine. Using data from a ninemonth field study, Perlow (1999) documents how interactive activities can foster insights and learning. More importantly, she also shows that these same activities have a high cost of individual productivity when they are not synchronized, phenomenon leading to "time famines" for knowledge workers. Coordination costs are documented in academic research for instance by Porac and colleagues who have found that the most heterogeneous collaboration in their study, Eco, had the most issues of communication and synchronization, but yet saw a large increase in productivity after its members had learnt to work together (Porac et al. 2004). Similarly, Cummings and Kiesler have found that multiuniversity scientific collaboration impose considerable coordination costs and leads to under-performance absent of a significant coordination effort (Cummings \& Kiesler 2007).

Further drivers of coordination costs have been explored in the social psychology literature which outlines several cognitive processes leading to inefficiencies in collaboration (Diehl \& Stroebe 1987). First, "production blocking" results from the chaotic interactions of the group, which impede the emergence of a consistent train of thoughts. Second, "evaluation apprehension" stems from the fear that some members might have of the others' judgment of their ideas. Finally, some authors have emphasized "information bias," which stems from a search for consensus within groups (Paulus 2007). It should be noted that a recent lab study by Girotra, Terwiesch and Ulrich (2010) finds that many of these drawbacks of collaboration can be mitigated through hybrid structures, in which individuals first work separately and then work together. Overall then, prior research suggests that the coordination difficulties stemming from collaboration in creative work are generally associated with a loss of individual productivity.

Credit allocation is the second major potential cost to collaboration. This arises because the credit is central to the reward system in knowledge work, particularly for scientific research conducted in the Academy in accordance with the norms of open science (Dasgupta and David 1994). However, while credit can be linked to a particular publication of "piece" of knowledge work, such credit must also be allocated to its producers - the authors. When researchers work alone and publish alone they serve as the sole recipients of credit for the quality of the output. In contrast, collaboration requires a more complex allocation calculus. The central importance of this issue for collaboration in creative work arises because as Merton noted: "[citations] are in truth central to the incentive system and an underlying sense of distributive justice that do much to energize the advancement of knowledge" (Merton 1988, p.621). Nonetheless, citations counts have been criticized for a number of reasons including the fact that independently of the article's "intrinsic" merits - the amount of citations it is likely to receive will depend on the year of its publication, its field, the journal where it is published, its style, its author, its availability online, etc (Bornmann \& Daniel 2008). While some have tried to disentangle quality from popularity 
(Salganik et al. 2006), such distinctions are problematic in creative work, where -as Stein's definition suggests ${ }^{5}$ - broad acceptation by the audience is often considered the only standard upon which quality can be assessed (Stein 1953).

In science, as in other types of creative work, impact is paramount. "For science to be advanced, it is not enough that fruitful ideas be originated or new experiments developed or new problems formulated or new methods instituted. The innovations must be effectively communicated to others. That, after all, is what we mean by a contribution ${ }^{6}$ to science - something given to the common fund of knowledge" (Merton 1968, p.59). It is of course possible that research developed via collaboration will have a greater impact because the larger team has a superior ability to communicate, mobilize support for, and bring attention to novel ideas. Collaborations play both a social and a cognitive role in this respect. In its social role, a group provides greater communication channels for the dissemination of novel ideas, thus enabling more visibility because each group member is endowed with a distinct set of relationships that he or she can use to promote the novel idea (e.g. Allen 1978; Tushman \& R. Katz 1980; Valderas 2007). Collaboration can also be instrumental in bringing legitimacy to a novel idea. Merton, for instance, noted that famous researchers lend visibility and credibility to a paper and that therefore students sometimes "feel that to have a better known name on the paper will be of help to them." (Merton 1968, p.57) a proposition recently validated in the case of the protocols submitted to the Internet Engineering Task Force (Simcoe \& Waguespack 2011). Similarly, in Hollywood, legitimacy can be gained through collaboration with individuals that are central to the network of producers (Cattani \& Ferriani 2008).

Nonetheless, while garnering greater attention overall, each individual contributor to the research must consider how this additional impact will shape their own credit allocation- a consideration that has not been heretofore examined. More specifically, researchers must consider the tradeoff between the greater impact overall and the credit allocation they receive and how it is spread among numerous authors. As the Hadron Collider paper illustrates, if individual authors only receive fractional credit allocation consistent with a linear function of the number of authors, collaboration becomes a much less appealing prospect (absent other modes of credit for research activities). As an illustration, consider the decision of a talented scientist - should she spend a year engaged in two collaborative projects each with one partner i.e. engaging $50 \%$ of her time in each of the two projects or should she work alone? That decision is tied importantly to the amount of credit received for collaborative projects compared with other projects. When a scientist devotes time to a collaborative project, not only must they take into account the balance of quality versus coordination costs but also the possibility that they receive only

\footnotetext{
${ }^{5}$ Morris Stein famously defined creative work as "a novel work that is accepted as tenable or useful or satisfying by a group in some point in time." (Stein 1953, p.311)

${ }^{6}$ Italicized in the original text
} 
fractional attribution for the resulting output. Thus, the collaborative projects that are actually observed will likely reflect the highest quality amongst those projects (an outcome that likely biases current results around the returns to collaboration).

Thus, credit allocation, as well as the norms associated with credit allocation must be incorporated into current empirical and theoretical perspectives regarding collaborative choices, particularly from an individual perspective. This is challenging because we have relatively little systematic data regarding credit allocation practices. The issue of authorship and credit has received widespread discussion in the scientific press, particularly with regards to "ghost" authors who make only limited contributions to a paper. In a recent release, publisher Elsevier noted that "Naming authors on a scientific paper ensures that the appropriate individuals get credit, and are accountable, for the research."7 Nonetheless, ours is the first paper we are aware of that incorporates credit allocation as well as coordination into a model of collaboration. It is also the first paper that attempts to use empirical data to derive a possible credit allocation function from observable collaborative choices of scientists over many years of research activity.

\section{FORMAL MODEL AND HYPOTHESES}

Empirical evaluation of the costs of collaboration is centrally an issue of measurement: while many approaches can be taken in observing the quality of research output and the level of collaboration in the form of citations and formal co-authorship respectively, these measures are potentially independent of coordination costs and the credit allocation costs because they are captured at the level of the publication. If, instead, we consider a scientist's collaborative choices at the individual year level, their portfolio of choices is more revealing of the tradeoffs in coordination and credit, thus providing a clearer window into collaborative choices well beyond observable quality differences.

To shed light on these tradeoffs and formulate hypotheses we have developed a formal model that explicitly considers the drivers of observable variables by formalizing a variety of the different underlying models that scientists might use to determine their own tradeoffs year on year. In this section, we provide that model and use it to motivate our empirical approach and the inferences that might be drawn from it. The goal of the model is to clearly exposit the benefits to collaboration and the possible credit allocation costs in a situation where scientific rewards from collaboration are clearly and consistently defined.

To this end, we focus on the decision of an individual scientist in managing their portfolio of activities. This requires several assumptions that, while stylized, are consistent with the evidence of scientists' broader choices and preferences. First, we assume that the scientist has discretion over the set

\footnotetext{
${ }^{7}$ http://ethics.elsevier.com/pdf/ETHICS AUTH01a.pdf
} 
of projects worked on and on the structure of collaboration for any given project. In reality of course, collaboration is a mutual decision (and an overture to collaboration could be rejected). For simplicity, we assume here that the focal scientist has full discretion over this choice. We will, however, comment on the implications of that simplifying assumption below.

Second, we assume that, not only is the scientist motivated by maximizing the total number of citations they receive for their portfolio of work, but also on the credit attribution of those citations: specifically they are motivated by the citations that are attributed to them rather than those attributed to

other collaborators. For instance, if the scientist completes and publishes a single author paper, they receive attribution consisting of the total amount of citations to that paper. However, when the scientist publishes a co-authored paper, their attribution may not be the full amount of citations to that paper. Instead, their 'share' depends upon a variety of factors. While there is a paucity of empirical evidence on attribution, a number of factors are likely to intermediate including the identity of the collaborator (e.g., relative rank, field) and number of collaborators. It should also be noted that, while we use the expression 'share of attribution' as this is a useful way of conceptualizing attribution, as will be seen below, we do not impose a requirement that the 'shares' of all scientists involved in a project sum to one.

Third, we assume that our scientist has a fixed amount of time to allocate across all projects and all of the activities that constitute those projects. In reality, a scientist could choose the amount of time they devote to research as opposed to other activities and this choice may be impacted by collaboration decisions. However, it is most simple to assume that scientists have a fixed allotment of time available for research and to assume that they are maximizing the effective allocation of that time. As a starting point, we build on the model of Becker and Murphy (1992). Their model concerned the division of labor in product activities and was neither about scientific research nor about collaboration in science. However, some elements of their model are well matched to the environment under consideration here. Where our model differs is in the concept of reward attribution and in the notion that exists a portfolio of projects; Becker and Murphy (1992) consider only one project.

\subsection{Model Set-Up and Assumptions}

Let us begin with the 'production function' for citations from a particular paper. Following Becker and Murphy, we assume that there is a continuum of tasks on the unit interval $s \in[0,1]$ that must be performed in order to produce a paper from a research project. To this end, suppose the number of citations for a paper, $i$, is $Q$ where:

$$
Q=\min _{0 \leq s \leq 1} Q(s)
$$

The Leontief production function captures the notion that each task, $s$, must be performed for output to be non-zero. The key assumption here is not the assumption of strict complements between tasks but their 
complementarity. Each task can itself be performed at a certain degree of quality, $Q(s)$, where we assume that $Q(s)=E(N) T^{\theta}(s)$ where $E_{i}$ is the productivity associated with total hours, $T(s)$, devoted to task $s, \theta \in(0,1)$ and $N$ is the total number of collaborators on the project. We assume that $E(1)=1$ and $E$ is increasing in $N$. This is a simple way of capturing the notion that specialization increases productivity. ${ }^{8}$ However, collaboration also requires time, $t(N)$, to be devoted to coordinating the activities of that team. ${ }^{9}$ As outlined above, past studies of collaboration have focused on understanding the net effect of changes in $E$ and $t$ with $N$. As we demonstrate below, measures of these are complicated by time constraints and the fact that scientists pursue a portfolio of projects with varying levels of collaboration over time.

\subsection{Equilibrium Collaboration for a Single Paper}

To begin, we focus on the allocation of time for a given paper. Suppose that a scientist, $n$, is assigned a set, $S_{n}$, of the tasks of a paper. Then total time devoted by $n$ to the paper is $T_{n}=t(N)+\int_{s \in S_{n}} T(s) d s$. We assume here that the opportunity cost of that time is $C_{n}\left(T_{n}\right)$; a function that will be modeled explicitly below. Given this, $n$ solves the following problem:

$$
\max _{\left\{T_{n}(s)_{\}_{s} \in S_{n}}\right.} \alpha(N) Q-C_{n}\left(T_{n}\right)
$$

where $\alpha(N) \leq 1$ is the fraction of total citations from $i$ attributable to $n$. We assume that if $N=1$, then $\alpha=1$. This fraction is considered to be independent of $Q$ realized. ${ }^{10}$

To derive the chosen allocation of time, as they are symmetric, we assume that time devoted to each task is equal. Thus, $\int_{s \in S_{n}} T(s) d s=S_{n} T(s)$ and $Q(s)=E(N) T^{\theta}(s)$ so the optimal $Q(s)$ satisfies the minimum of this or the minimal quality achieved for a task by collaborating scientists.

To complete the model, assume that if there are $N$ collaborators to a project, they split the number

\footnotetext{
${ }^{8}$ Becker and Murphy (1992) assume that productivity increases also require an allocation of time but ultimately this reduces to specialization increasing productivity. For notational simplicity, we remove that extraneous layer of endogeneity here.

${ }^{9}$ Becker and Murphy (1992) did not model coordination costs specifically and assumed that those costs were a function $C(N)$. Here we provide an additional layer of endogeneity consistent with our notion that scientists are allocating time across projects and thus, time spent in coordinating activities as an opportunity cost determined by time not allocated to other projects.

${ }^{10}$ One can imagine that the attribution may come from market assessments as to the relative contribution of collaborators in a scientific team and such attribution may itself depend on the performance of tasks the scientist is known for. Thus, the fraction of total citations attributable to $n$ may be dependent upon the realized quality of a project. This is a complex problem that we assume away here but is investigated in more detail, theoretically, in Gans and Murray (2013).
} 
of tasks between them equally. This is a natural assumption if scientists are symmetric ${ }^{11}$ and results in $Q=E(N) T^{\theta}(s)$. Holding the time allocation choices of other collaborators as given, the scientist chooses $T_{n}$ to maximize:

$$
\max _{T_{n}} \alpha(N) E(N)\left(N\left(T_{n}-t(N)\right)\right)^{\theta}-C\left(T_{n}\right)
$$

Note that if $\min _{m \neq n} T_{m}<T_{n}$, it is optimal to lower $T_{n}$ to that minimum. Thus, there is potentially a continuum of equilibria in this game. The equilibrium with the highest allocation of time, $T_{n}^{*}$, is characterized by the first order condition:

$$
\alpha(N) E(N) N \theta\left(N\left(T_{n}-t(N)\right)\right)^{\theta-1}=C^{\prime}\left(T_{n}^{*}\right)
$$

This equation plays a key role in what follows. ${ }^{12}$ Specifically, we focus on the equilibrium with the highest allocation of time.

\subsection{Equilibrium Collaboration with Multiple Papers}

Our purpose here is to measure the impact of collaboration on productivity and, in the process, make inferences about the benefits and costs of collaboration and also the structure of the scientific reward function for research teams. The above analysis shows that collaboration can be beneficial because of the exploitation of specialization and the division of labor but incurs a potential cost in coordination. However, collaboration also impacts time available for a scientist to pursue other papers; in particular, sole-authored projects without collaboration. Here we introduce that option into the model.

What follows is an examination of the impact of introducing collaborators on one paper in the portfolio of papers that a scientist is involved in producing during a given time period. To this end, we assume that the scientist can allocate time to an additional paper. That paper is single authored. Consequently, there are no advantages from the division of labor but the scientist faces no coordination costs and receives attribution equal to the full value (in terms of quality or citations) of the paper. We otherwise assume that the paper's production function is equivalent to that specified above.

For the single-authored paper in the portfolio, if we assume that the total time allocation a scientist has is 1 , then

$$
C^{\prime}\left(T_{n}\right)=\theta\left(1-T_{n}\right)^{\theta-1}
$$

Using this we can solve for the optimal time allocation to the collaborative project given $N$ :

\footnotetext{
${ }^{11}$ This is a strong simplifying assumption as it assumes that no regard to differences in the opportunity cost in time are taken into account when allocating tasks between collaborating scientists. However, the qualitative predictions of the model that we focus on for this paper would not be changed if this assumption were relaxed.

${ }^{12}$ It could also be used to analyze other issues such as the optimal team size. These are issues explored in Jiang, Thursby and Thursby (2012).
} 


$$
\begin{aligned}
& \alpha(N) E(N) N \theta\left(N\left(T_{n}-t(N)\right)\right)^{\theta-1}=\theta\left(1-T_{n}\right)^{\theta-1} \\
& \Rightarrow T_{n}^{*}=t(N)+\frac{1-t(N)}{1+N(\alpha(N) E(N) N)^{1 /(\theta-1)}} \\
& \Rightarrow 1-T_{n}^{*}=(1-t(N)) \frac{N(\alpha(N) E(N) N)^{1 /(\theta-1)}}{1+N(\alpha(N) E(N) N)^{1 /(\theta-1)}}
\end{aligned}
$$

Given this, scientists face a choice. They can collaborate on one of the papers with $N$ participants (leaving a second paper single authored) or they can pursue two single authored papers. The choice depends not only on the quality improvement (if any) arising from collaboration but also from the time cost (if any) diverted from single authored papers as well as the level of attribution the scientist expects from the collaborative project.

Our model exposes the central issue with empirical analyses of the impact of collaboration on scientific productivity and quality: the challenges with studies that focus purely on collaboration versus non-collaboration without accounting for time considerations or individual scientist effects. Because individual scientists are constrained in the time they have at any particular moment, collaborative projects impact time allocation and hence, the observed quality of collaborative and single authored projects. In particular, from (6) note that $T_{n}^{*}$ is decreasing in $N(\alpha(N) E(N) N)^{1 /(\theta-1)}$ and

$$
\begin{aligned}
\frac{\partial\left(N(\alpha(N) E(N) N)^{1 /(\theta-1)}\right)}{\partial N}=( & \alpha(N) E(N) N)^{1 /(\theta-1)} \\
& +\frac{N}{\theta-1}(\alpha(N) E(N) N)^{(2-\theta) /(\theta-1)}\left(\frac{\partial \alpha}{\partial N} E(N) N+\frac{\partial E}{\partial N} \alpha(N) N+\alpha(N) E(N)\right)
\end{aligned}
$$

This expression is positive if $\alpha(N) E(N) N$ does not vary much with $N$. In this situation, an increase in collaboration may allow the scientist to reduce the time allocated to the collaborative paper in favor of the non-collaborative paper; consequently, studies focused on collaboration may understate the productivity of collaboration. Alternatively, in cases when the impact of collaboration on productivity is high (i.e., $E(N)$ varies substantially with $N$ ) time will be drawn towards the collaborative project away from the single authored paper overstating the pure productivity of collaboration. From an empirical standpoint, it is only by controlling for scientist-year fixed effects that these distortions can be mitigated. A similar issue arises with respect to coordination costs from collaboration: these result in a reduction in 'research time' for both the collaborative and single authored project. Again, to properly identify the portfolio effects of collaboration, year effects are required to exploit variations in portfolio mix over time.

There are three hypotheses that can be tested with this model. The first concerns the average quality of publications:

H1: A scientist has higher quality average publications in years in which they collaborate more.

This is a direct implication of the notion that scientists are decision-makers with regard to the collaboration choice. As collaborative publications involve a fractional allocation of credit, i.e., $\alpha(N)<1$, 
a scientist will only collaborate if this results in a higher quality over their portfolio of projects.

Second, collaborative projects involve costs in terms of a reduction in the quantity of papers accredited to scientists:

H2: In years when the scientist collaborates more, fractional publications fall.

In our model, when the scientist single-authors all papers, they have an output of 2 papers while if they collaborates on one of those papers, their fractional output is $1+\alpha(N)$ or $1+1 / N$ in the case of simple fractional allocation. Note that the converse could be true: collaboration may 'free up' a scientist's time with the result that this hypothesis will be refuted as more single authored projects or alternative collaborations are pursued. This will indicate that $\alpha(N) E(N) N$ does not vary much with $N$.

Third, suppose that collaborative opportunities are equally or harder to come by than individual research projects, then the 'rate of return' to collaboration in a particular year should be (weakly) positive:

H3: For a given $\alpha(N)$, the fractional quality of the portfolio attributed to the scientist in years they collaborate more should be no less than the quality of the portfolio they achieve in years they collaborate less.

The intuition here is that a scientist takes their expected attribution from collaboration as given and chooses their portfolio to maximize their attributed quality. Thus, for a posited $\alpha(N)$ if we see a negative return, this is evidence that the posited $\alpha(N)$ is not consistent with observed collaborative behavior.

\section{EMPIRICAL APPROACH}

\subsection{Data and Setting}

Given the challenges associated with empirical analysis, we have chosen to focus on the collaborative choices and publication outcomes of a sample of scientists over a long period of time, thus allowing us to include both individual and year fixed effects in our analysis. This contrasts with approaches that compare outputs at the publication level.

Our setting is a comprehensive dataset of research publication activity at a single university - the Massachusetts Institute of Technology - including the research output over the thirty-one year period 1976-2006 of more than 650 faculty members in 7 departments from the Schools of Science and the School of Engineering. This focus on a single university over time is particularly appealing for several reasons. First, a scientist's choice of whether or not to collaborate is little constrained by formal organizational structure. Second, these choices can be easily traced out from one year to the next by following authorship on publications. Third, "quality" can be analyzed using the (albeit imperfect) metric of citations. Fourth, as noted above our setting offers the opportunity to control for individual effects

allowing us to tease out the impact of collaboration (Woodman et al. 1993). Lastly by selecting one 
institution, we can control for institutional setting. Our choice of MIT is not only one of convenience: it has been shown that prestigious institutions participate more fully in collaborative science (Adams et al. 2005; Jones et al. 2008) and, thus, using MIT allows us to examine the "leading edge" of collaboration.

The core of the study is a sample of publishing faculty members drawn from the annual lists as faculty members at MIT (in the Academic Bulletin). Criteria for inclusion are the following: First, we include faculty from the following seven departments - Electrical Engineering and Computer Science, Chemical Engineering, Material Science and Engineering, Mechanical Engineering, Biology, Chemistry and Physics. These were selected because they include both science and engineering disciplines and are among the most well established parts of the MIT research activity. Second, faculty must be listed for at least a consecutive period of 3 years in order to avoid counting visiting professors, whose participation in research groups of particular size might be systematically biased by their short stay. Third, we chose the period 1976 to 2006 because of ISI data limitations and because 1975 was the year in which the still stable departmental arrangements were established. ${ }^{13}$ Fourth, we exclude all the scientists who ever took part in projects with more than 20 authors due to the decoupling of authorship and contribution for specific projects and particular fields (Knorr-Cetina 1999): using ISI subfields, this included scientists in 5 "Big Science" subfields - Astronomy \& Astrophysics, Multidisciplinary Physics, Nuclear Physics, Instruments \& Instrumentation, Particles \& Fields Physics. (Note, however, that our results are robust to the inclusion on these scientists in our data).

We identified 846 individual scientists from our set of Departmental and year criteria. We then excluded 128 (most of whom were already Emeriti Professors in 1976) due to a lack of any publication record for the time period. We further excluded 57 scientists who had taken part to projects that included more than 20 authors. We use our list of 661 publishing faculty as the basis of our analysis. For these people, we collected individual level information including $\mathrm{PhD}$ year and topic from UMI Proquest Dissertation Database, as well as departmental affiliation and seniority from MIT course catalogue for the 31 years (Assistant, Associate, Full Professor or Emeritus). We collected all the articles written by our scientists during their time at MIT using ISI Web of Science. Between 1976 and 2006, the 661 scientists stayed at MIT for 5,964 faculty-years and wrote 21,054 publications.

\subsection{Dependent Variables}

Quality: We measure quality ( $Q$ in our formal model) by observing the average number of citations received by a scientist for all the papers he or she published in a given year. As noted above, while citation giving is a part of normal science, citation counts are an imperfect measure of quality,

\footnotetext{
${ }^{13}$ In 1975 the department of Electrical Engineering expanded to become Electrical Engineering and Computer Science and the department of Metallurgy and Materials Sciences merged into Materials Science and Engineering.
} 
impact or credit. However, across a sample of publications, citations are a relatively objective and convenient measure of an article's quality and impact and have therefore been widely used in science evaluation (Furman \& Stern 2011; Leahey 2007; Wuchty et al. 2007). Practically, we used the number of citations received by 2008 (Cites) as a measure of impact at the paper-level. Using this metric, we can calculate the yearly quality of the scientist's publications by observing the average number of citations that they receive. For scientist $i$ in year $t$, the quality of publication $k$ was measured as the average number of citations cites $_{k}$ in that year's publications: Cites $_{i t}=E\left(\text { Cites }_{k}\right)_{i t}$.

In order to examine whether variation in marketing capability is driving our results about quality, we check the robustness of all our results using another proxy for work quality: the average Journal Impact Factor (2009 data) of every scientist-year. We could not find a JIF for $16.2 \%$ of the publications the discrepancy coming from low ranking journals, conference proceedings, journals which have disappeared and those who have changed name. Each model using JIF was run twice, a first time considering that the missing JIF was 0 , a second time by imputing the missing data using the article number of citations. These methods consistently led to the same results.

Productivity (Quantity): We measure NPubs $s_{i t}$, the productivity of a scientist's work ( $E$ in our formal model) by keeping the input constant (a scientist-year) and observing the number of papers published in a given year. It is worth noting that of course publication data is only a proxy for the number of projects that a scientist is involved with; publications are only the disclosed final outcomes of projects and may therefore undercount the total number of projects if some lead to no publications. Nonetheless, our ability to aggregate publications to the individual faculty-year level serves as an important step towards accounting for inputs into collaboration (Girotra et al. 2010, p.593). Beyond simply capturing NPubs, our approach builds on Lee and Bozeman (2005) and also examines the "factional count" of paper published. As the most simple functional form of fractional counting of productivity, we compute Frac_Pubs the sum of "papers shares" directly attributed to the scientist. In other words, if the scientist $i$ in the year $t$ has published $n$ papers, each of which includes a number NAuthors $s_{k}$ of authors, their fractional publication count for that year is:

$$
\text { Frac_Pubs }_{i t}=\sum_{k=1}^{n} \alpha\left(\text { NAuthor }_{k}\right) \text { where } n=N P u b s_{i t}
$$

Credit Allocation: As detailed in our formal model, we consider scientists' motivation to collaborate to be dependent on $\alpha(N)$, the share of their research output that is attributed to them (rather than to their collaborators). The specific functional form of this attribution is an empirical question that we examine in this paper. For a given $\alpha(N)$, we compute the number of yearly citations attributed to a scientist's work by summing the citations attributed to the author for every paper of the year. In other words, if the scientist $i$ in the year $t$ has published $n$ papers $(k)$, each of which includes $N A u t h o r s_{k}$ and 
has received Cites $_{k}$ by 2008 , their attributed citation count for that year is:

$$
\text { Att_Cites }_{i t}=\sum_{k=1}^{n} \text { Cites }_{k} * \alpha\left(\text { NAuthor }_{k}\right) \text { where } n=N P u b s_{i t}
$$

At one extreme, if $\alpha(N)=1$, then the credit for a collaborative paper is not split and each author claims the entire credit for each coauthored paper and its citations. At the other extreme, if $\alpha(N)=1 / N$, then the scientists split the credit across every author and the sum of shares of all scientists involved in a project sums to one. A third possible form is that $\alpha(N)=1 / \sqrt{N}$ - i.e., that scientists can claim less credit for a coauthored than for a sole-authored paper, but that the sum of the shares of credit attributed to all the scientists in a coauthored paper is superior to one. ${ }^{14}$

\subsection{Independent Variable-Collaboration}

We measured the extent of collaboration during a scientist-year by considering the mean number of coauthors ( $N$ in the formal model) for all the publications of that year (see Wuchty et al. 2007; Adams et al. 2005; Jones et al. 2008). We obtain the number of coauthors on a project (NAuthor $S_{k}$ ) by counting the numbers of names in the author field of each of our publications (also referred to as the coauthorship index (Bordons et al. 1996)). While co-authorship remains a practice as a form of currency in the cycles of scientific credit (Latour \& Woolgar 1986), it only reflects actual collaboration to the extent that authorship reflects participation. A few studies have noted that this measure is an imperfect one (Subramanyam 1983; J. S. Katz \& Martin 1997; Cronin et al. 2004): Distinguished researchers are sometimes added to the authorship list despite the fact that their contribution is relatively minor, a practice known as "guest authorship." Conversely, "ghost authors" are individuals who are not recognized as coauthors despite their significant contribution. Recent work has shown that norms of inclusion vary by discipline and that inclusion is often positively correlated to a scientist's social standing (Biagioli 2003; Häussler \& Sauermann 2011). Decoupling contribution and authorship, increases measurement error in our analysis: to avoid some these issues we exclude from our sample scientists who have taken part to any publication with more than twenty coauthors. In our regressions, we also control for disciplinary, temporal, individual and career-related patterns. For scientist $i$ in year $t$, collaboration was measured as the average number of authors NAuthors $_{k}$ in that year publications: NAuthors $s_{i t}=$ $E\left(\text { NAuthors }_{k}\right)_{i t}$.

\footnotetext{
${ }^{14}$ Other synthetic measures of performance have been suggested such as the index $h$ which measures for each individual scientist the number of papers with citation superior or equal to $h$ (Hirsch 2005). According to this measure, a scientist would have an $h$-index of 20 if he or she has published 20 papers having received more than 20 citations and all the other published papers have received fewer than 20 citations. While this measure is attractive because of its simplicity and ability to synthesize quantity and quality at the level of the individual, this measure is not adapted to measuring within-individual variation in performance over time.
} 


\subsection{Control Variables}

Individual Ability: Individual aptitudes are widely believed to be a predictor of creativity and quality (Amabile et al. 1996; Woodman et al. 1993). Prior research has also shown that better scientists tend to work in larger groups (H. Zuckerman 1972). Controlling for individual-level variance in creative ability is, therefore, crucial if we are to disentangle the impact of collaboration on the quality of scientific work. An important advantage of our setting is that we have a number of observations per individual and can therefore introduce in our models a dummy variable for each of our scientist.

Career Stage: Scientific creativity and propensity to collaborate are widely believed to vary over their career span (H. Zuckerman 1972; Stephan \& Levin 2001; Jones 2009). It is, therefore, important to control for such career-level variation. We therefore introduce an indicator variable for each of the scientist's career stage: Assistant Professor, Associate Professor, Professor and Professor Emeritus.

Department-Year: General citations patterns vary from one year to the next and are known to be increasing over time due to the fast expansion of knowledge production (Cawkell 1976). Moreover, this expansion might vary from one discipline to the next. To control for such variation, we included an indicator variable for all department-years in the sample.

Authoring Position: In order to check the robustness of our findings and control for authoring position, we introduce a dummy variable when the focal scientist is the first (last) author. At the level of the faculty-year, our First Author variable (Last Author variable) is the propensity of the scientist to be first (last) author for all of their year's publications.

\subsection{Empirical Approach}

H1: A scientist has higher quality average publications in years in which they collaborate more: We test hypothesis 1 by assessing the impact of an individual's annual collaborative behavior on the average quality of the scientist's publications. The mean number of co-authors for the year proxies for collaboration and $E\left(\text { Cites }_{k}\right)_{i t}$ is our measure of quality (we also measure the average journal impact factor as an alternative measure of quality). Because we can control for individual and contextual characteristics, we are building on and bringing further robustness to prior results that collaboration is associated with higher quality output (Adams et al. 2005; Wuchty et al. 2007). We use an OLS regression (Adams \& Griliches 1998; Adams et al. 2005) with department-year, individual scientist, and career stage fixed effect. In all our regressions, robust standard errors are clustered at the level of the individual scientist to account for the non-independence of observations from the same author. We estimate:

$$
\ln \left(\text { Cites }_{i t}\right)=f\left(\varepsilon_{i t} ; N \text { Authors } s_{i t}+\beta_{i}+\delta_{t}+\theta_{i c}+X_{i t}\right)
$$

where $\beta_{i}$ is the fixed effect for each scientist, $\delta_{t}$ is the fixed effect for each department-year, $\theta_{i c}$ is the fixed-effect for career stage and $X_{i t}$ represents a vector of variables (potentially including a squared term 
as well as measures of authoring position) which may be associated with output quality.

H2: In years when the scientist collaborates more, fractional publications fall: We test $\mathrm{H} 2$ by studying the impact of an individual's yearly collaborative behavior on the quantity of the scientist's publications. We, therefore, examine productivity by studying the relationship between collaboration and the number of papers published that year using the Frac_Pubs measure to account for the fractional number of publication (and compared to the total number of publication NPubs). Because the number of attributed publications per year is a continuous variable skewed to the right, we used the natural $\log$ to alleviate this skewness and used OLS with robust standard errors for our estimation. As earlier, we used scientist, career stage and department-year fixed effects. Specifically we estimate the following equations:

$$
\ln \left(\text { Frac_Pubs }_{i t}\right)=f\left(\varepsilon_{i t} ; \text { NAuthors }_{i t}+\beta_{i}+\delta_{t}+\theta_{i c}+X_{i t}\right)
$$

where, as in the previous equation, $\beta_{i}$ is the fixed effect for each scientist, $\delta_{t}$ is the fixed effect for each department-year, $\theta_{i c}$ is the fixed effect for career stage and $X_{i t}$ represents a vector of variables which may be associated with productivity.

H3: For a given $\alpha(N)$, the fractional quality of the portfolio attributed to the scientist in years they collaborate more should be no less than the quality of the portfolio they achieve in years they collaborate less. As is apparent from our formal model, the benefit of collaboration relative to noncollaboration will depend on $\alpha(\mathrm{N})$ the share of the credit attributed to the scientist for a collaborative paper. If scientists behave rationally and maximize their attributed citations, we should find that the hypothesized positive impact of collaboration on quality and its negative impact on quantity would cancel one another. Assuming that collaborative opportunities are scarcer than non-collaborative ones (since collaborators might be hard to find), we might expect that scientists systematically under-collaborate and, therefore, find that the overall returns to collaboration might appear positive. We test hypothesis 3 by examining attributed citations as a function of collaboration for a given $\alpha(\mathrm{N})$. As earlier, we take the natural $\log$ of the fractional number of citations and use an OLS estimator with robust standard errors, as well as scientist, career-stage and department-year fixed effects:

$$
\ln \left(\text { Att_Cites }_{i t}\right)=f\left(\varepsilon_{i t} ; \text { NAuthors }_{i t}+\beta_{i}+\delta_{t}+\theta_{i c}+X_{i t}\right)
$$

According to $\mathrm{H} 3$, one would not expect that the overall returns to collaboration be negative. Assuming that scientists optimize the citations that are attributed to them every year, for a given $\alpha(N)$, finding negative returns to collaboration would indicate that in our chosen $\alpha(N)$ probably underestimates the actual credit that scientists are getting for the work that they produce. While testing H3, we will consider three different functions for $\alpha(N)$ as described above.

We deepen our understanding of the mechanisms at work shaping the impact of collaboration on quality and productivity by distinguish the effect of different types of co-authorship. Specifically, we compare the impact on the focal scientist of collaborations with a more junior scientist, a more senior 
scientist and a scientist of the same rank. We can also explore the impact of collaborating across departments and/or with non-PIs. To do so, we limit our analysis the subset of the sample of scientistyears in which every published paper involved only MIT-affiliated authors (2,273 faculty-years and 4,617 publications) allowing us to identify all the MIT PIs, their department and their career stage as well as count the number of non-PIs on each paper.

\section{RESULTS}

\subsection{Descriptive Statistics}

Table 1 and 2 present the main variables of our analysis. Over the 5,964 faculty-year observations we have data on a total of 21,054 publications. This allows us to track the extent to which the researcher collaborated by observing the average number of coauthors for the year. Mean group size (NAuthors) is 3.8 authors. Collaboration at the faculty-year level varies between 1 and 20. Scientists did not collaborate at all only during 157 faculty-years (2.6\%). In 64\% of the faculty-years average group size was between 2 and 4 authors. The entire distribution of group sizes in the data is plotted in Figure 1.

\section{[Figure 1 approximately here]}

The key dependent variables in our data are quality (average number of forward citations received by the papers produced in a faculty-year), productivity (quantity of papers attributed to the scientist per year), and the overall credit (citations) attributed to the scientist for a year of work. With regards to quality (Cites), the average number of forward citations received (by 2008) by the papers written in a faculty-year is 41.3. Turning to productivity, the MIT researchers published an average of 3.5 papers per year (i.e. NPubs is 3.5). However, Frac_Pubs (i.e. assuming $\alpha(N)=1 / N$ ) is only 1.1. Both quality and productivity are highly skewed across faculty-years. We also measure the credit attributed to the scientist of the year of work using the three proposed functional forms:

- If $\alpha(N)=1$, the mean Att_Cites is 165.1 citations

- If $\alpha(N)=1 / \sqrt{N}$, then mean Att_Cites is 86.4 citations

- If $\alpha(N)=1 / N$ then mean Att_Cites is 48.7 citations.

Table 2 presents the correlation coefficients of our main variables. It highlights that average group size and year are positively correlated $(+0.23)$, i.e. collaboration in our sample has evolved over time toward larger groups. Also note that productivity has also been increasing over time, and that this holds across both NPubs and Frac_Pubs (0.20 and 0.11 respectively). Consistent with the prior literature, we find a positive correlation between collaboration (NAuthors) and quality (Cites) $(+0.09)$. Table 2 also 
shows that the correlation between collaboration on the one hand and yearly productivity on the other is highly dependent whether we consider NPubs or Frac_Pubs: For $\alpha(N)=1$, collaboration is positively correlated with productivity $(+0.13)$ i.e. not surprisingly, on average, collaboration is associated with more authored papers but the correlation is negative for Frac_Pubs (-0.14). With regards to credit attribution, for $\alpha(N)=1$ the correlation is positive $(+0.11)$ but for $\alpha(N)=1 / N$ the correlation is almost null (-0.01). Interestingly, the correlation between productivity and quality appears overall positive, i.e. we do not find evidence of any intrinsic quality-quantity trade-off in academic research.

[Table 1 and 2 approximately here]

\subsection{Econometric Analysis of Hypotheses}

Our hypotheses 1, 2 and 3 are tested in Table 3. Model (3-1) confirms Hypothesis 1 and in doing so, adds robustness to the result of prior studies in showing that choosing to collaborate in larger groups leads on average to higher quality outputs since we can control for individual and context level idiosyncrasies. The highly significant positive coefficient on group size confirms our hypothesis 1 . More specifically the coefficient of 0.099 can be interpreted as an increase by about $10 \%$ of the number of citations received per paper for the addition of one collaborator on average for the year.

Our hypothesis 2, that collaboration is associated with a loss in productivity is tested in models (3-2) and (3-3). At the level of the year at work, we find in (3-2) that the choice to collaborate in larger groups is not associated with a higher number of authored publications per year. This result is particularly interesting since we have seen in Table 2 that the two variables are overall positively correlated in the data. On average, however, it seems that at the level of the scientist's yearly choice, the potential productivity gains stemming from specialization and division of labor are counterbalanced by the costs of coordination. This result is even more striking if we consider that, by choosing collaboration, scientists cannot really be "allocated" all the resulting publications but rather might consider their fractional contribution to the stock of published knowledge i.e. $\alpha(N)<1$. Model (3-3) shows that collaboration is associated on average with lower attributed productivity. In the case of fractional publication counts (3-3), group size is negatively correlated (-0.069).

Finally, models (3-4) to (3-6) explore credit attribution from collaboration. Model (3-4) shows that the quality benefit from collaboration is on average superior to its productivity cost where $\alpha(N)=1$. This result can be interpreted in two ways. First, if one believes that scientists get all the credit for each of their coauthored publication, then scientists might be systematically under-collaborating. A second, more plausible interpretation of the result is that $\alpha(N)<1-$ i.e., that scientists actually share some of the credit with their collaborators. Models (3-5) and (3-6) propose different credit sharing functions $\alpha(N)$. $\alpha(N)=1 / \sqrt{N}$ is explored in (3-5) and is consistent with scientists in our dataset rationally using 
collaboration to maximize their yearly attributed impact. Indeed, model (3-5) shows no statistically significant correlation between collaboration and yearly attributed impact overall. Model (3-6) uses a more strict credit sharing function in which $\alpha(N)=1 / N$ and shows a statistically significant negative relationship between collaboration and yearly attributed impact. This result suggests that the credit for a given collaborative paper is not shared across coauthors in a way that sums up to 1 . Taken together these results suggest that the credit sharing function of $\alpha(N)=1 / \sqrt{N}$ is most closely associated with rational collaborative behavior all else being equal.

\section{[Table 3 approximately here]}

Figure 2 presents the regression estimates when we dichotomize our main independent variable, average collaboration size for a faculty-year. We can note that the upper left graph that the relationship between collaboration and output quality seems to have decreasing returns and to pick at 8 collaborators. The middle row graphs display the relationship between collaboration and productivity for NPubs $(\alpha(N)=1)$ and for Frac pubs $(\alpha(N)=1 / N)$. Interestingly, for relatively large collaborations (average coauthoring groups of 5 or more for the year), the relationship between collaboration and productivity is negative for Npubs and Frac_pubs. The difference between publication attribution functions comes from relatively small collaboration levels. If coauthors do not "share" the papers they write but instead account for all their papers equally, then collaboration is positively associated with productivity for collaborations of up to three coauthors on average per year. However, if papers are split across coauthors, then collaboration is associated with negative (fractional) productivity for every value of $N$. This result shows that scientists produce fewer papers when they collaborate than when they work alone - but individually, each of them will have more lines on their $\mathrm{CV}$ as long as $N<5$ on average for the year.

The bottom graphs also show striking consistencies across $\alpha(N)$ functions. For yearly average collaboration of up to 3 coauthors, collaboration is associated with more attributed citations. The different results that we observed in models (3-4) to (3-6) stem from average yearly group size of 4 or more. If credit does not get split, then these highly collaborative years are associated with more attributed citations. However, if it does get split, these years are associated with similar levels of $(\alpha(N)=1 / \sqrt{N})$ or fewer $(\alpha(N)=1 / N)$ attributed citations.

[Figure 2 approximately here]

\subsection{Robustness Analysis}

In Tables 4 and 5, we subject our results to additional robustness tests. We begin by examining the relationship between collaboration and quality. While citations have been broadly used as a measure of publication quality, one could worry that they might be associated with some marketing advantage that 
larger groups might have. In model (4-1), we use an alternative measure of paper quality: the journal impact factor (JIF) of the publishing outlet. For the few publications in the dataset for which we could not find a JIF, we imputed the latter based on the citations that the articles had received. ${ }^{15}$ We find that scientists not only receive more citations on average for the publications on which they collaborate more, they also get published in journals of higher impact factor. Models (4-2) to (4-4) examine whether and how authorship position impacts our findings. ${ }^{16}$ It is, for instance, possible that in those years in which our scientists collaborate more they are attributed fewer citations because they do not have the "controlling position" of being a first or last author. One way to control for authoring position and to avoid the use of fractional measures is to assign to a scientist only the publications in which he or she is the last author - and give him or her the entire credit for the publication and resulting citations. Our results are very consistent with those that we find when using $\alpha(N)=1 / N$.

\section{[Table 4 approximately here]}

While fractional measures have been used in bibliometric studies for many years (for an early example see (Price \& Beaver 1966)), one could also worry that our results for the case in which $\alpha(N)=1 / N$ might be mechanically driven by the fact that our main independent variable, collaboration, is also in the denominator of our fractional measures of output quantity and overall contribution. This worry, however, is unfounded here because what we are really interested in is precisely whether there are decreasing returns to collaboration. In other words, a negative coefficient in our fractional regressions is evidence of a concave relationship between collaboration and creative output. Although most visible through fractional measures, our result can equally be observed without using any fractional variable as in Models (4-3) and (4-4).

Model (5-1) and (5-2) achieve the same results in yet another manner; they show that collaboration is associated with significant decreasing returns to scale concerning both quantity and yearly contribution (as measured through forward citations). The relationship is concave: $N$ scientists working separately during a given time publish more articles and receive more forward citations than $N$ scientists working together. The inflection points implied by the coefficients in these two models are respectively 5.4 in (5-1) and 9.6 in (5-2). They are also visible in the left-hand side graphs presented in Figure 2 (where alpha(N)=1). Finally, one might worry that our results primarily hold for publication of average quality. If one believes that only the very best publications really matter, then one might be interested in the relationship between collaboration and taking part to a very high impact publication.

\footnotetext{
${ }^{15}$ In another model, we also replaced missing JIF with the value 0 since journals for which we could not find information are likely to be of minor importance. The results remained unchanged.

${ }^{16}$ Note that some of this variance is already accounted for by the fact that we include in all of our model career-stage fixed effect (authorship position is closely related to career-stage)
} 
Models (5-3) to (5-5) consider only the top 5\% of the paper published by department-year and shows that the general patterns observed overall also holds for this subset of publications only.

[Table 5 approximately here]

\subsection{Different Collaborators}

In the subset of 2,273 faculty-years in which MIT PIs only publish with a coauthor that was affiliated with MIT, we explore the impact of different types of research collaborators. Table 6 provides the descriptive statistics for this subsample. For these within-MIT years, PIs on average collaborated with 0.3 other MIT PIs and 1.7 non-PIs per year. About half of the inter-PI collaborations (54\%) took place between scientists of the same rank, and collaboration took place both within-department and acrossdepartments at a similar rate ( 0.11 and 0.15 collaborating PIs per year respectively).

\section{[Table 6 approximately here]}

Table 7 illustrates that our main results from Table 3 still hold for our subsample of MIT PIs in years in which they have only chosen to collaborate with other MIT PIs. Specifically, researchers who collaborate in larger groups produce higher quality papers (7-1) and get fewer fractional papers (7-3) although if $\alpha(N)=1$ i.e., they consider all their publications (NPubs) then the number of PIs has no significant impact (see (7-2)).

\section{[Table 7 approximately here]}

The relationship between collaboration and quality might be driven by a number of distinct mechanisms including increased time-input for collaborative work, but also potentially cross-fertilization from different perspectives and higher credibility of larger groups. These mechanisms would lead to conflicting predictions regarding whether scientists would profit more from collaborating within their department or with PIs from other departments. If the positive relationship between collaboration and quality is driven by credibility alone, then within-department collaboration would be the most advantageous. If it was driven by cross-fertilization, then cross-department collaboration might particularly lead to higher quality papers. Finally, if it is simply driven by higher input, then both types of collaboration should have a similar positive impact on paper quality. Model (8-1) shows that crossdepartment collaboration is much more strongly associated with higher quality papers than withindepartment work. This result suggests that the main mechanism driving the positive relationship between collaboration and quality is cross-fertilization rather than credibility or simply higher input.

\section{[Table 8 approximately here]}

We have also seen that the relationship between collaboration and productivity might be driven by two conflicting mechanisms: coordination cost and division of labor/specialization. The fact that we find an overall negative relationship between collaboration and productivity suggests that the coordination 
costs outweigh on average the gains from specialization. Should we then conclude that there is no gain from a division of labor in scientific research? Models (8-2) and (8-3) show the contrary. We find that the "productivity cost" to collaboration is lower for collaborations that span departmental boundaries, indicating that division of labor does decrease the cost to collaboration. Overall, then, we find that the apparent trade-off between quality and productivity is not the same for every type of collaboration. Specifically, we find collaboration has more benefits and is less costly when it involves individuals from different departments. This overall difference between within and across department collaboration is also visible when studying the citations attributed to individual scientists.

Models (8-4) to (8-6) show that unless scientists get all the credit for collaborative work, withindepartment collaboration is associated with fewer attributed yearly citations. In contrast, across department collaboration is associated with significantly more attributed citations if $\alpha(N)=1$, and no significantly fewer attributed citations if $\alpha(N)=1 / \sqrt{N}$.

\section{[Table 9 approximately here]}

Finally, the rank of the collaborator might also influence the collaboration's outcome. On the one hand, a prestigious collaborator might increase both the quality and the visibility of the work output. On the other hand, senior collaborators might also free-ride on the efforts of more junior coauthors. In order to study the influence of these mechanisms in our context, we distinguish in Table 9 between collaborating with a more junior scientist, collaborating with a scientist of the same rank or collaborating with a more senior PI. Our results are more consistent with the free-riding mechanism. Model (9-1) shows that collaborating with a more senior person does not increase quality but does have a cost on productivity, especially if the collaboration is inter-departmental. Models (9-4) to (9-6) show that scientists seem to perform less well when they collaborate with someone who is senior to them. Like collaborations with more senior coauthors, collaborations with more junior ones are not associated with a statistically significant gain in output quality. However, Models (9-2) and (9-3) show that the productivity cost in this case appears considerably lower, leading to a relatively more positive impact of collaboration on attributed citations (Models (9-4) to (9-6)). Interestingly, the positive impact of collaboration on quality and its negative impact on productivity are particularly salient in the case of collaboration with someone of the same rank.

Overall, our analysis of the mechanisms driving our main results provides a richer picture of the micro-foundations of the apparent quality-productivity tradeoff associated with collaboration choices in creative work. Collaboration is particularly associated with higher quality output when it provides more opportunities for cross-fertilization of ideas by bringing together scientists of a similar rank and from different backgrounds. Collaboration also involves a significant productivity loss (at least if $\alpha(N)<1$ ). This loss is particularly salient if the coauthor is of a more senior rank. Interestingly, opportunities for 
division of labor - through cross-departmental collaboration - seem to diminish this productivity loss. In sum, these results indicate that the apparent tradeoff between quality and quantity associated with scientists' collaboration choices might be driven by the decision to allocate one's time in a way that might lead to coordination costs and free-riding but that might also foster cross-fertilization of ideas and a productive division of labor.

\section{DISCUSSION AND CONCLUSIONS}

Considering collaboration at the level of the individual provides insights into the reasons why autonomous creative workers choose to work together or with others with different expertise or with different positions in the status hierarchy. As any researcher knows, the decision to collaborate is endogenous and the focus on creative output (e.g., publications, patents) in prior studies conceals important potential variables that contour collaborative choices. Only through a simultaneous exploration of the benefits and costs of collaboration for individuals can we really seek to understand the phenomenon of collaboration. In this paper, we have taken a step in this direction by developing a theoretical model of collaboration that considers both the potential benefits in terms of productivity, but also the coordination costs and the costs in terms of credit allocation among individuals. Our empirical focus on individual choices over a period of time enables us to hold "talent" constant, thus overcoming (to some extent), the heterogeneous nature of individual knowledge workers. We thus explore these tradeoffs in the organization of scientific work by considering a scientist's decision to allocate her fixed time to more or less collaborative projects.

We find that collaboration is associated with important tradeoffs, including higher quality publications, lower individual productivity and disproportionate credit attribution-i.e. that credit for a given collaborative paper is shared across coauthors in a way that sums up to more than 1 . The size of these effects is considerable. A scientist working during a year with one other person on average rather than working alone can hope to receive over $60 \%$ more citations per published paper. They will also be able to show more publications on their $\mathrm{CV}$ despite the fact that their fractional productivity, in fact, decreased by over $15 \%$--indicating that the two together publish considerably less than they would, had they worked separately. Importantly, scientists' collaboration behavior is consistent with a credit premium of over $33 \%{ }^{17}$ for collaborating with one person per year on average as opposed to working alone. Taken together, these results suggest that the "net value" of collaboration in creative work might be superior for the credit-seeking worker than it is for the output-focused manager or policy-maker. The benefits of

\footnotetext{
${ }^{17}$ Percentages were computed using estimates shown in Figure 2. Average credit attribution (yearly citations received) for a collaboration of two when $\alpha(N)=1 / N$ is 18 citations by 2008. It is 24 citations when $\alpha(N)=1 / \sqrt{ } N$. In comparison, credit received for the average sole authored year is about 15 citations.
} 
collaborations are particularly high and its costs are particularly low when the collaboration brings together individuals having different skills and perspectives - as in the case of cross-departmental collaborations. On the other hand, the drawbacks of collaboration are particularly salient when scientists collaborate with a person that is senior to them. We find no evidence that junior scientists benefit from collaborating from somebody that is more established in their field.

We regard our results as an important first step in bringing the perspective of the time-conscious and credit-seeking knowledge worker to the debate on collaboration and creativity. Despite the recent surge in interest in collaboration for creativity by organization scholars, the large majority of these studies has focused on the output from the collaboration (typically the quality of the work completed). Our contribution was made possible by a departure from previous studies that have examined how to optimize the quality of a given piece of work. Indeed, we have complemented this approach by switching unit of analysis and focusing on the creative worker's decision to spend their time working alone or in groups of smaller or larger sizes. In so doing, we were able to disentangle a number of tradeoffs associated with collaboration and creativity.

This research is not without its limitations: First, the decision to collaborate in smaller or larger groups is a complex one and is likely to involve other considerations than output quality, individual productivity and credit allocation. For instance, collaboration might have a financial cost or be endeavored to learn rather than to maximize individual credit. Second, we are not able to directly measure the scientists' credit allocation function - which is likely to vary substantially across disciplines (see for instance Maciejovsky et al. 2009). Instead we study that function indirectly by first developing a formal model of scientific collaborative choice and then by testing whether its predictions are consistent with the behavior that we observe in our data. Third, absent an experimental design, we cannot be sure that our empirical results are not at least partially driven by task heterogeneity. This endogeneity could be particularly problematic if tasks that can only accommodate large groups were important in ways that cannot be captured through paper citations or publication journal impact factor. Nonetheless, our setting provides the advantage of presenting the real choices made by creative workers in a number of disciplines over three decades. Our theoretical model generates predictions that are consistent with scientists' behavior and are robust across a variety of specifications. The fact that our findings are obtained after including individual fixed effects is also important- in other words our approach accounts for the variation in the choices made by the same scientist over the course of their career. Analysis of different types of collaborator further illuminates the various mechanisms underlying the tradeoffs that we observe.

Our study is only a first step toward understanding the benefits and drawbacks of collaboration for creative workers. Other correlates are likely to shape collaboration's "net value" beyond what we can observe in our data. On the input side, the amount of financial resources and equipment necessary for a 
given task are likely to vary with group size (Beaver \& Rosen 1978). On the output side, collaboration is often described as a particularly enjoyable organization of work and a paramount driver of circulation of ideas, and learning (J. S. Katz \& Martin 1997). Overall, the relationship between these costs and benefits is likely to depend on the group's intensity, structure, and experience (e.g., Porac et al. 2004). These are all important nuances which are likely to impact the net value of collaboration, and which we have not been able to study here. The importance of continuing the investigation of collaboration in the context of creative work should not be understated. As the nature of work is changing, more attention might usefully be brought to the fact that in practice, collaboration is an organization of work that has complex and perhaps distinct implications for creative workers on the one hand and managers and policy-makers on the other. 


\section{REFERENCES}

Adams, J.D. et al., 2005. Scientific teams and institutional collaborations: Evidence from U.S. universities, 1981-1999. Research Policy, 34(3), pp.259-285.

Adams, J.D. \& Griliches, Z., 1998. Research productivity in a system of universities. Annales d'Economie et de Statistique, pp.127-162.

Allen, T.J., 1978. Managing the flow of technology, MIT press Cambridge, MA.

Amabile, T.M. et al., 1996. Assessing the Work Environment for Creativity. The Academy of Management Journal, 39(5), pp.1154-1184.

Ancona, D.G. \& Caldwell, D.F., 1992. Bridging the Boundary: External Activity and Performance in Organizational Teams. Administrative Science Quarterly, 37(4), pp.634-665.

Beaver, D.B., 2001. Reflections on scientific collaboration (and its study): past, present, and future. Scientometrics, 52(3), pp.365-377.

Beaver, D.B. \& Rosen, R., 1978. Studies in scientific collaboration. Scientometrics, 1(1), pp.65-84.

Becker, G.S. \& Murphy, K.M., 1992. The Division of Labor, Coordination Costs, and Knowledge. The Quarterly Journal of Economics, 107(4), pp.1137-1160.

Biagioli, M., 2003. Rights or Rewards. In Scientific Authorship: credit and intellectual property in science. pp. 253-279.

Bordons, M. et al., 1996. Local, domestic and international scientific collaboration in biomedical research. Scientometrics, 37(2), pp.279-295.

Bornmann, L. \& Daniel, H.-D., 2008. What do citation counts measure? A review of studies on citing behavior. Journal of Documentation, 64(1), pp.45-80.

Burt, R.S., 2004. Structural Holes and Good Ideas. American Journal of Sociology, 110(2), pp.349-399.

Cattani, G. \& Ferriani, S., 2008. A Core/Periphery Perspective on Individual Creative Performance: Social Networks and Cinematic Achievements in the Hollywood Film Industry. ORGANIZATION SCIENCE, 19(6), pp.824-844.

Cawkell, A.E., 1976. Citations, obsolescence, enduring articles, and multiple authorships. Journal of Documentation, 32(1).

Cronin, B., Shaw, D. \& La Barre, K., 2004. Visible, Less Visible, and Invisible Work: Patterns of Collaboration in 20th Century Chemistry. Journal of the American Society for Information Science \& Technology, 55(2), pp.160-168.

Cummings, J.N., 2004. Work Groups, Structural Diversity, and Knowledge Sharing in a Global Organization. Management Science, 50(3), pp.352-364.

Cummings, J.N. \& Kiesler, S., 2007. Coordination costs and project outcomes in multi-university collaborations. Research Policy, 36(10), pp.1620-1634.

Dasgupta, P. \& David, P.A. 1984. Towards a new economics of science. Research Policy, 23, pp.487521.

Diehl, M. \& Stroebe, W., 1987. Productivity loss in brainstorming groups: Toward the solution of a riddle.

Ding, W.W. et al., 2010. The Impact of Information Technology on Academic Scientists' Productivity and Collaboration Patterns. Management Science, 56(9), pp.1439-1461. 
Dumaine, B., 1994. The Trouble with Teams. Fortune.

Dumaine, B. \& Gustke, C., 1990. Who Needs a Boss? Fortune.

Edmondson, A., 1999. Psychological Safety and Learning Behavior in Work Teams. Administrative Science Quarterly, 44(2), pp.350-383.

Engers, M., Gans, J.S., Grant, S. \& King, S.P., 1999. First Author Conditions. Journal of Political Economy, 107 (4), pp.859-883.

Fleming, L., 2007. Breakthroughs and the "Long Tail" of innovation. MIT Sloan Management Review, 49(1), p.69.

Fleming, L., Mingo, S. \& Chen, D., 2007. Collaborative Brokerage, Generative Creativity, and Creative Success. Administrative Science Quarterly, 52(3), pp.443-475.

Furman, J. \& Stern, S., 2011. Climbing atop the shoulders of giants: The impact of institutions on cumulative research. American Economic Review, 101(5), pp.1933-1963.

Gans, J.S. \& Murray, F. 2013. Markets for Scientific Attribution. mimeo., MIT.

Gilfillan, S.C., 1935. Inventing the ship, Follett Chicago, IL.

Girotra, K., Terwiesch, C. \& Ulrich, K.T., 2010. Idea Generation and the Quality of the Best Idea. Management Science, 56(4), pp.591-605.

Hara, N. et al., 2003. An emerging view of scientific collaboration: Scientists' perspectives on collaboration and factors that impact collaboration. Journal of the American Society for Information Science and Technology, 54(10).

Hargadon, A., 2008. Creativity That Works. In Handbook of Organizational Creativity. Psychology Press.

Hargadon, A., 2003. How breakthroughs happen: The surprising truth about how companies innovate, Harvard Business School Pr.

Hargadon, A. \& Bechky, B., 2006. When Collections of Creatives Become Creative Collectives: A Field Study of Problem Solving at Work. ORGANIZATION SCIENCE, 17(4), pp.484-500.

Hargadon, A. \& Sutton, R., 1997. Technology Brokering and Innovation in a Product Development Firm. Administrative Science Quarterly, 42(4), pp.716-749.

Häussler, C. \& Sauermann, H., 2011. Credit Where Credit is Due? The Impact of Project Contribution and Social Factors on Authorship and Inventorship. SSRN eLibrary. Available at: $\mathrm{http}: / /$ ssrn.com/paper=1750240 [Accessed June 12, 2011].

Hirsch, J.E., 2005. An index to quantify an individual's scientific research output. Proceedings of the National Academy of Sciences of the United States of America, 102(46), pp.16569-16572.

Hoerr, J., 1989. The Payoff from Teamwork: The Gains in Quality are Substantial-So Why Isn't It Spreading Faster. Business Week (European Edition), pp.36-42.

Holmstrom, B. 1982. Moral Hazard in Teams. Bell Journal of Economics, 13, pp.324-340.

Jiang, L., Thursby, J. and Thursby, M. 2012. Scientific Disclosure and the Faces of Competition. REER Conference Presentation, Georgia Tech.

Johansson, F., 2004. The Medici effect: breakthrough insights at the intersection of ideas, concepts, and cultures, Harvard Business Press.

Jones, B., 2009. The Burden of Knowledge and the "Death of the Renaissance Man": Is Innovation Getting Harder? Review of Economic Studies, 76(1), pp.283-317. 
Jones, B., Wuchty, S. \& Uzzi, B., 2008. Multi-University Research Teams: Shifting Impact, Geography, and Stratification in Science. Science, 322(5905), p.1259.

Katz, J.S. \& Martin, B.R., 1997. What is research collaboration? Research Policy, 26(1), pp.1-18.

Katzenbach, J.R., Smith, D.K. \& Bookspan, M., 1993. The wisdom of teams, Harvard Business School Press Boston.

Knorr-Cetina, K., 1999. Epistemic Cultures: How the Sciences Make Knowledge, Harvard University Press Cambridge, MA.

Koplowitz, R. et al., 2009. Benchmarking Your Collaboration Strategy. Available at: http://www.forrester.com/rb/Research/benchmarking_collaboration_strategy/q/id/48336/t/2.

Landry, R. \& Amara, N., 1998. The impact of transaction costs on the institutional structuration of collaborative academic research. Research Policy, 27(9), pp.901-913.

Latour, B. \& Woolgar, S., 1986. Laboratory life: The construction of scientific facts, Princeton University Press.

Leahey, E., 2007. Not by productivity alone: How visibility and specialization contribute to academic earnings. American sociological review, 72(4), pp.533-561.

Lee, S. \& Bozeman, B., 2005. The Impact of Research Collaboration on Scientific Productivity. Social Studies of Science, 35(5), pp.673-702.

Maciejovsky, B., Budescu, D.V. \& Ariely, D., 2009. Research Note--The Researcher as a Consumer of Scientific Publications: How Do Name-Ordering Conventions Affect Inferences About Contribution Credits? MARKETING SCIENCE, 28(3), pp.589-598.

McAfee, R.P. \& McMillan, J., 1991. Optimal Contracts for Teams. International Economic Review, 32, pp.561-577.

Melin, G., 2000. Pragmatism and self-organization: Research collaboration on the individual level. Research Policy, 29(1), pp.31-40.

Merton, R.K., 1968. The Matthew Effect in Science The reward and communication systems of science are considered. Science, 159(3810), p.56.

Merton, R.K., 1988. The Matthew Effect in Science, II: Cumulative Advantage and the Symbolism of Intellectual Property. Isis, 79(4), pp.606-623.

Newman, M.E.J., 2001. The structure of scientific collaboration networks. Available at: http://www.pnas.org/content/98/2/404.abstract?ijkey=795320f82b4665524ad6611 c618f9236aa76 0799\&keytype2=tf_ipsecsha [Accessed December 19, 2008].

Obstfeld, D., 2005. Social networks, the tertius iungens orientation, and involvement in innovation. Administrative Science Quarterly, 50(1), pp.100-130.

Orsburn, J.D. \& Moran, L., 2000. The new self-directed work teams: Mastering the challenge, McGrawHill.

Paulus, P.B., 2007. Fostering creativity in groups and teams. The handbook of organizational creativity, pp.159-182.

Paulus, P.B. \& Nijstad, B.A., 2003. Group creativity: Innovation through collaboration, Oxford University Press.

Porac, J.F. et al., 2004. Human capital heterogeneity, collaborative relationships, and publication patterns in a multidisciplinary scientific alliance: a comparative case study of two scientific teams. Research Policy, 33(4), pp.661-678. 
Price, D.J. \& Beaver, D.B., 1966. Collaboration in an invisible college. Am Psychol, 1966, pp.1011-8.

Reagans, R., Argote, L. \& Brooks, D., 2005. Individual Experience and Experience Working Together: Predicting Learning Rates from Knowing Who Knows What and Knowing How to Work Together. Management Science, 51(6), pp.869-881.

Reagans, R. \& Zuckerman, E.W., 2001. Networks, Diversity, and Productivity: The Social Capital of Corporate R\&D Teams. Organization Science, 12(4), pp.502-517.

Salganik, M.J., Dodds, P.S. \& Watts, D.J., 2006. Experimental Study of Inequality and Unpredictability in an Artificial Cultural Market. Science, 311(5762), pp.854-856.

Simcoe, T.S. \& Waguespack, D.M., 2011. Status, Quality, and Attention: What's in a (Missing) Name? Management Science, 57(2), pp.274-290.

Singh, J. \& Fleming, L., 2010. Lone Inventors as Sources of Breakthroughs: Myth or Reality? Management Science, 56(1), pp.41-56.

Stein, M.I., 1953. Creativity and culture. Journal of Psychology, 36(2), pp.311-322.

Stokols, D. et al., 2005. In vivo studies of transdisciplinary scientific collaboration Lessons learned and implications for active living Research. American journal of preventive medicine, 28(2S2), pp.202-213.

Subramanyam, K., 1983. Bibliometric studies of research collaboration: A review. Journal of information Science, 6(1), p.33.

Taylor, A. \& Greve, H.R., 2006. Superman or the fantastic four? Knowledge combination and experience in innovative teams. Academy of Management Journal, 49(4), p.723.

Tushman, M.L. \& Katz, R., 1980. External Communication and Project Performance: An Investigation into the Role of Gatekeepers. Management Science, 26(11), pp.1071-1085.

Uzzi, B. \& Spiro, J., 2005. Collaboration and Creativity: The Small World Problem. American Journal of Sociology, 111(2), pp.447-504.

Valderas, J.M., 2007. Why do team-authored papers get cited more? Science (New York, NY), 317(5844), p.1496.

Von Hippel, E.A., 2005. Democratizing Innovation. SSRN eLibrary. Available at: http://papers.ssrn.com/sol3/papers.cfm?abstract_id=712763 [Accessed June 14, 2009].

Woodman, R.W., Sawyer, J.E. \& Griffin, R.W., 1993. Toward a Theory of Organizational Creativity. The Academy of Management Review, 18(2), pp.293-321.

Wray, B.K., 2002. The Epistemic Significance of Collaborative Research. Philosophy of Science, 69(1), pp.150-168.

Wuchty, S., Jones, B. \& Uzzi, B., 2007. The Increasing Dominance of Teams in Production of Knowledge. Science, 316(5827), p.1036.

Zare, R.N., 1997. Editorial: Knowledge and Distributed Intelligence. Science, 275(5303), p.1047.

Zuckerman, H., 1972. Age, Aging, and Age Structure in Science, reprinted in: Robert K. Merton, 1973. The Sociology of Science. 
TABLE 1: DESCRIPTIVE STATISTICS AT THE INDIVIDUAL-YEAR AND PUBLICATION LEVELS

\begin{tabular}{|l|c|c|c|c|c|c|c|c|}
\hline \multirow{2}{*}{ Variable } & \multicolumn{3}{|c}{$\begin{array}{c}\text { PUBLICATION LEVEL } \\
(\mathrm{n}=21,054)\end{array}$} & \multicolumn{3}{c|}{$\begin{array}{c}\text { INDIVIDUAL-YEAR LEVEL } \\
(\mathrm{n}=5,964)\end{array}$} \\
\cline { 2 - 9 } & Mean & Std. Dev. & Min & Max & Mean & Std. Dev. & Min & Max \\
\hline Average Group Size (Nauthors) & 4.1 & 2.3 & 1 & 20 & 3.8 & 1.9 & 1 & 20 \\
\hline Average Forward Citations (Cites) & 46.8 & 111.9 & 0 & 4810 & 41.3 & 86.9 & 0 & 2595 \\
\hline Productivity -- alpha(N)=1 (NPubs) & n.a. & n.a. & n.a. & n.a. & 3.5 & 3.7 & 1 & 47 \\
\hline Productivity -- alpha(N)=1/N(Frac_Pubs) & n.a. & n.a. & n.a. & n.a. & 1.1 & 1.1 & 0.1 & 9.7 \\
\hline Att_Cites -- alpha(N)=1 & 46.8 & 111.9 & 0 & 4810 & 165.1 & 388.8 & 0 & 8852 \\
\hline Att_Cites -- alpha(N)=1/sqrt(N) & 24.5 & 67.2 & 0 & 4810 & 86.4 & 211.7 & 0 & 4947 \\
\hline Att_Cites -- alpha(N)=1/N & 13.8 & 51 & 0 & 4810 & 48.7 & 135.4 & 0 & 4819 \\
\hline N_Highly Cited Publications & 0.05 & 0.22 & 0 & 1 & 0.18 & 0.52 & 0 & 8 \\
\hline Frac_Highly Cited Publications & 0.01 & 0.07 & 0 & 1 & 0.05 & 0.17 & 0 & 2 \\
\hline Average JIF (missing values imputed) & 4.86 & 5.57 & 0 & 52.59 & 4.46 & 4.62 & 0.024 & 29.89 \\
\hline Average JIF (missing values 0) & 4.1 & 5.82 & 0 & 52.59 & 3.57 & 4.76 & 0 & 29.89 \\
\hline Last Authored Paper & 0.63 & 0.48 & 0 & 1 & 0.61 & 0.39 & 0 & 1 \\
\hline First Authored Paper & 0.08 & 0.27 & 0 & 1 & 0.12 & 0.29 & 0 & 1 \\
\hline Year & 1995 & 8.6 & 1976 & 2006 & 1993.2 & 8.8 & 1976 & 2006 \\
\hline
\end{tabular}

TABLE 2: CORRELATION TABLE, MAIN VARIABLES, INDIVIDUAL-YEAR LEVEL (5,964 observations)

\begin{tabular}{|l|c|c|c|c|c|c|c|c|}
\hline & $\mathbf{1}$ & $\mathbf{2}$ & $\mathbf{3}$ & $\mathbf{4}$ & $\mathbf{5}$ & $\mathbf{6}$ & $\mathbf{7}$ & $\mathbf{8}$ \\
\hline 1. NAuthors (mean group size) & 1 & & & & & & & \\
\hline 2. Cites (av. forward cites) & $0.0944^{*}$ & 1 & & & & & & \\
\hline 3. NPubs & $0.1254^{*}$ & $0.0602^{*}$ & 1 & & & & & \\
\hline 4. Frac_Pubs -- alpha(N)=1/N & $-0.1414^{*}$ & 0.0415 & $0.9026^{*}$ & 1 & & & & \\
\hline 5. Att_Cites -- alpha(N)=1 & $0.1068^{*}$ & $0.6097^{*}$ & $0.5092^{*}$ & $0.4712^{*}$ & 1 & & & \\
\hline 6. Att_Cites -- alpha(N)=1/sqrt(N) & 0.0414 & $0.6210^{*}$ & $0.4742^{*}$ & $0.4786^{*}$ & $0.9711^{*}$ & 1 & & \\
\hline 7. Att_Cites -- alpha(N)=1/N & -0.011 & $0.6095^{*}$ & $0.4022^{*}$ & $0.4415^{*}$ & $0.8794^{*}$ & $0.9655^{*}$ & 1 & \\
\hline 8. Year & $0.2301 *$ & $-0.1416^{*}$ & $0.1967^{*}$ & $0.1149^{*}$ & $-0.0520^{*}$ & $-0.0742^{*}$ & $-0.0848^{*}$ & 1 \\
\hline
\end{tabular}

Significance level: * $\mathrm{p}<0.001$ 
TABLE 3: THE EFFECT OF COLLABORATION CHOICE ON QUALITY, QUANTITY \& CREDIT

\begin{tabular}{|l|c|c|c|c|c|c|}
\hline \multirow{5}{*}{} & QUALITY & \multicolumn{2}{|c|}{ QUANTITY } & \multicolumn{3}{c|}{ CREDIT } \\
\cline { 2 - 7 } & $\begin{array}{c}\text { DV=log(1+Cites } \\
\text { by paper) }\end{array}$ & \multicolumn{2}{|c|}{ DV=log(1+Pubs $)$} & \multicolumn{3}{|c|}{ DV=log(1+Att_Cites) } \\
\cline { 2 - 7 } & & NPubs & Frac_Pubs & alpha(N)=1 & alpha(N)=1/sqrt(N) & alpha(N)=1/N \\
\cline { 2 - 7 } & $(3-1)$ & $(3-2)$ & $(3-3)$ & $(3-4)$ & $(3-5)$ & $(3-6)$ \\
\hline Department-Year FE & Yes & Yes & Yes & Yes & Yes & Yes \\
\hline Scientist FE & Yes & Yes & Yes & Yes & Yes & Yes \\
\hline Career Stage FE & Yes & Yes & Yes & Yes & Yes & Yes \\
\hline Group Size & $0.0990^{* * *}$ & -0.00582 & $-0.0688^{* * *}$ & $0.0919^{* * *}$ & -0.00303 & $-0.0834^{* * *}$ \\
\hline & -0.01 & 0 & 0 & -0.01 & -0.01 & -0.01 \\
\hline Constant & $3.127^{* * *}$ & $0.864^{* * *}$ & $0.653^{* * *}$ & $3.405^{* * *}$ & $3.253^{* * *}$ & $3.079^{* * *}$ \\
\hline & -0.17 & -0.05 & -0.03 & -0.19 & -0.18 & -0.17 \\
\hline Observations & 5964 & 5964 & 5964 & 5964 & 5964 & 5964 \\
\hline R-squared & 0.24 & 0.136 & 0.21 & 0.157 & 0.16 & 0.183 \\
\hline
\end{tabular}

OLS; Robust standard errors in parentheses are clustered at the level of the individual MIT scientist

Significance level: *** $\mathrm{p}<0.01, * * \mathrm{p}<0.05, * \mathrm{p}<0.1$

\section{TABLE 4: ROBUSTNESS CHECKS (1)}

\begin{tabular}{|c|c|c|c|c|}
\hline & JOURNAL IMPACT & \multicolumn{3}{|c|}{ CREDIT GIVEN TO LAST AUTHOR ONLY $\dagger$} \\
\hline & QUALITY & QUALITY & QUANTITY & $\begin{array}{c}\text { YEARLY } \\
\text { CITATIONS }\end{array}$ \\
\hline & $\begin{array}{l}\text { OLS; DV= Av. JIF for the year; } \\
\text { missing JIF imputed based on } \\
\text { pub cites }\end{array}$ & $\begin{array}{c}\text { OLS; DV }= \\
\log (1+\text { Cites })\end{array}$ & $\begin{array}{c}\text { OLS; DV }=\log (1+ \\
\text { NPubs-LastAuthor })\end{array}$ & $\begin{array}{c}\text { OLS; } \mathrm{DV}=\mathrm{DV}=\log (1+ \\
\text { Att_Cites-LastAuthor })\end{array}$ \\
\hline & $(4-1)$ & $(4-2)$ & $(4-3)$ & $(4-4)$ \\
\hline Department-Year FE & Yes & Yes & Yes & Yes \\
\hline Scientist FE & Yes & Yes & Yes & Yes \\
\hline Career Stage FE & Yes & Yes & Yes & Yes \\
\hline \multirow[t]{2}{*}{ Group Size } & $0.387 * * *$ & $0.117 * * *$ & $-0.0846 * * *$ & $-0.199 * * *$ \\
\hline & $(0.06)$ & $(0.02)$ & $(0.01)$ & $(0.02)$ \\
\hline \multirow[t]{2}{*}{ Constant } & $4.456 * * *$ & $2.890 * * *$ & $0.708 * * *$ & $2.832 * * *$ \\
\hline & $(0.44)$ & $(0.23)$ & $(0.06)$ & $(0.24)$ \\
\hline Observations & 5,964 & 2,265 & 5,964 & 5,964 \\
\hline R-squared & 0.09 & 0.28 & 0.16 & 0.131 \\
\hline
\end{tabular}

OLS; Robust standard errors in parentheses are clustered at the level of the individual MIT scientist

Significance level: *** $\mathrm{p}<0.01,{ }^{* *} \mathrm{p}<0.05,{ }^{*} \mathrm{p}<0.1$

$\dagger$ Since (total) yearly collaboration is of interest, the "Group Size" variable was not recalculated to include only last-authored paper $\$$ All cites attributed to last author only 
TABLE 5: ROBUSTNESS CHECKS (2)

\begin{tabular}{|c|c|c|c|c|c|}
\hline & \multicolumn{2}{|c|}{ CONCAVENESS } & \multicolumn{3}{|c|}{ TOP QUALITY PUBLICATIONS } \\
\hline & \multirow{2}{*}{$\begin{array}{c}\text { QUANTITY } \\
\text { OLS; } \\
\text { DV }=\log (1+ \\
\text { NPubs })\end{array}$} & \multirow{2}{*}{$\begin{array}{c}\text { CREDIT } \\
\text { OLS } ; \\
\mathrm{DV}=\log (1+ \\
\text { Att_Cites }) \mathrm{N}=1\end{array}$} & \multicolumn{3}{|c|}{ CREDIT } \\
\hline & & & $\begin{array}{c}\mathrm{OLS} ; \\
\mathrm{DV}=\underset{\log (1+\text { Att_Cites })}{\mathrm{alpha}(\mathrm{N})=1}\end{array}$ & 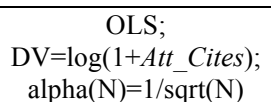 & $\begin{array}{c}\mathrm{OLS} ; \\
\mathrm{DV}=\log (1+\text { Att_Cites }) \\
\text { alpha }(\mathrm{N})=1 / \mathrm{N}\end{array}$ \\
\hline & $(5-1)$ & $(5-2)$ & $(5-3)$ & $(5-4)$ & $(5-5)$ \\
\hline Department-Year FE & Yes & Yes & Yes & Yes & Yes \\
\hline Scientist FE & Yes & Yes & Yes & Yes & Yes \\
\hline Career Stage FE & Yes & Yes & Yes & Yes & Yes \\
\hline \multirow[t]{2}{*}{ Group Size } & $0.0492 * * *$ & $0.250 * * *$ & $0.00457 * *$ & -0.000532 & $-0.00247 * * *$ \\
\hline & $(0.01)$ & $(0.04)$ & $(0.00)$ & $(0.00)$ & $(0.00)$ \\
\hline \multirow[t]{2}{*}{ Group Size Squared } & $-0.00454 * * *$ & $-0.0130 * * *$ & & & \\
\hline & $(0.00)$ & $(0.00)$ & & & \\
\hline \multirow[t]{2}{*}{ Constant } & $0.782 * * *$ & $3.098 * * *$ & $0.0921 * * *$ & $0.0767 * * *$ & $0.0599 * * *$ \\
\hline & $(0.05)$ & $(0.21)$ & $(0.03)$ & $(0.02)$ & $(0.01)$ \\
\hline Observations & 5,964 & 5,964 & 5,964 & 5,964 & 5,964 \\
\hline R-squared & 0.142 & 0.164 & 0.041 & 0.036 & 0.036 \\
\hline
\end{tabular}

OLS; Robust standard errors in parentheses are clustered at the level of the individual MIT scientist

Significance level: $* * * \mathrm{p}<0.01, * * \mathrm{p}<0.05, * \mathrm{p}<0.1$

TABLE 6: WITHIN MIT COLLABORATION -- DESCRIPTIVE STATISTICS

\begin{tabular}{|c|c|c|c|c|c|c|c|c|}
\hline \multirow{2}{*}{ Variable } & \multicolumn{4}{|c|}{$\begin{array}{l}\text { PUBLICATION LEVEL } \\
(n=4,617 \text { out of } 21,054)\end{array}$} & \multicolumn{4}{|c|}{$\begin{array}{l}\text { INDIVIDUAL-YEAR LEVEL } \\
(n=2,273 \text { out of } 5,964)\end{array}$} \\
\hline & Mean & Std. Dev. & Min & Max & Mean & $\begin{array}{l}\text { Std. } \\
\text { Dev. }\end{array}$ & Min & Max \\
\hline \multicolumn{9}{|l|}{ Overall Group Profile } \\
\hline \# PIs & 1.3 & 0.5 & 1 & 4 & 1.3 & 0.5 & 1 & 4 \\
\hline \# non-PIs & 1.7 & 1.3 & 0 & 10 & 1.7 & 1.2 & 0 & 10 \\
\hline \multicolumn{9}{|c|}{ Breakdown of Collaborating PIs by Position of the Collaborator } \\
\hline \# junior PIs & 0.05 & 0.2 & 0 & 3 & 0.06 & 0.2 & 0 & 3 \\
\hline \# PIs with same position & 0.14 & 0.4 & 0 & 3 & 0.13 & 0.3 & 0 & 3 \\
\hline \# senior PIs & 0.07 & 0.3 & 0 & 3 & 0.08 & 0.3 & 0 & 3 \\
\hline \multicolumn{9}{|c|}{ Breakdown of Collaborating PIs by Department of the Collaborator } \\
\hline \# PIs from the same department & 0.11 & 0.3 & 0 & 3 & 0.19 & 0.4 & 0 & 3 \\
\hline \# PIs from a different department & 0.15 & 0.4 & 0 & 3 & 0.09 & 0.3 & 0 & 2 \\
\hline
\end{tabular}


TABLE 7: THE EFFECT OF PI COLLABORATION CHOICES WITHIN MIT

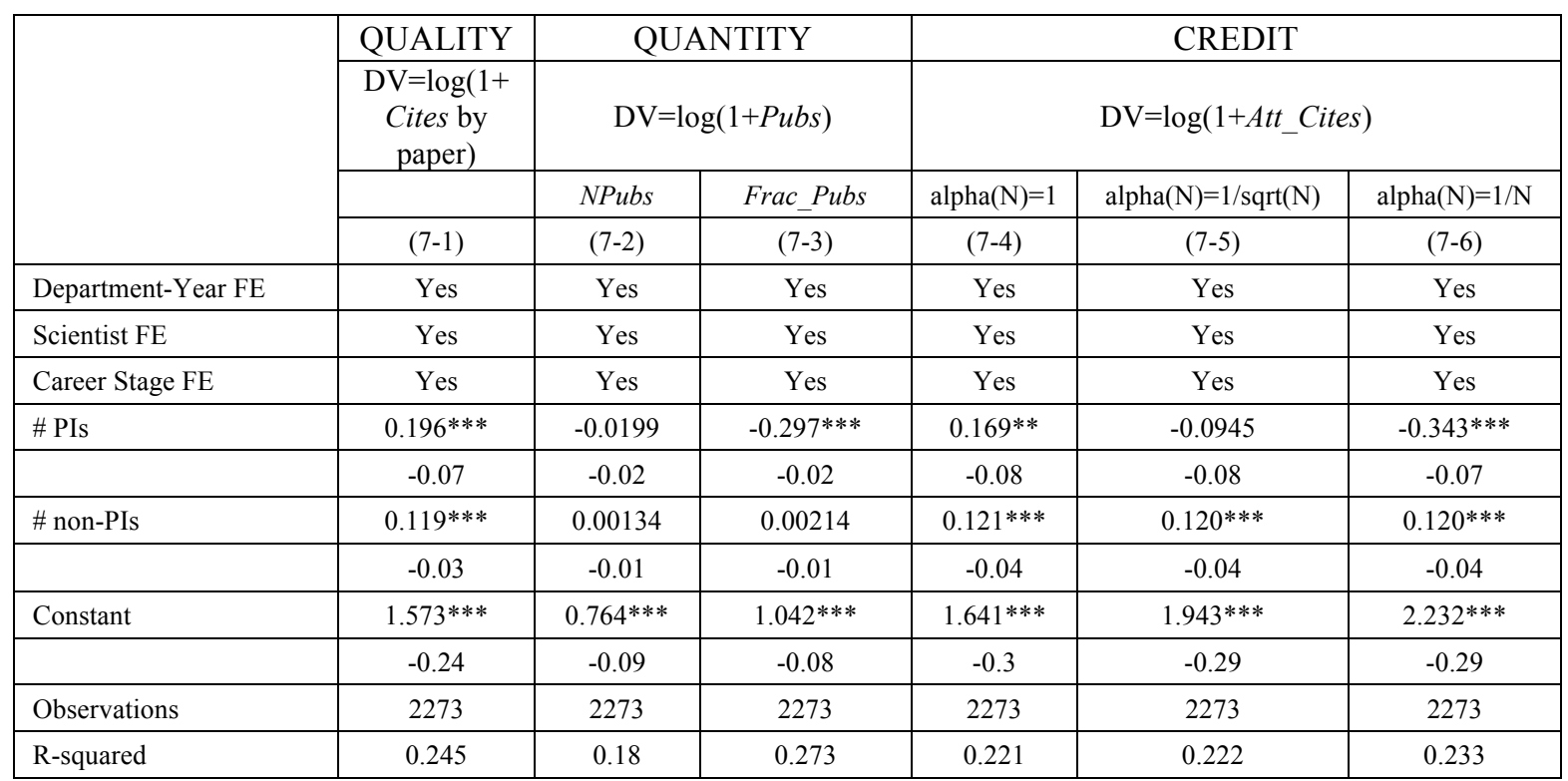

OLS; Robust standard errors in parentheses are clustered at the level of the individual MIT scientist

Significance level: $* * * \mathrm{p}<0.01,{ }^{* *} \mathrm{p}<0.05,{ }^{*} \mathrm{p}<0.1$

\section{TABLE 8: THE EFFECT OF PI COLLABORATION WITHIN AND ACROSS DEPARTMENTS}

\begin{tabular}{|c|c|c|c|c|c|c|}
\hline & QUALITY & \multicolumn{2}{|c|}{ QUANTITY } & \multicolumn{3}{|c|}{ CREDIT } \\
\hline & $\begin{array}{c}\mathrm{DV}=\log (1+ \\
\text { Cites by }\end{array}$ & \multicolumn{2}{|c|}{$\mathrm{DV}=\log (1+P u b s)$} & \multicolumn{3}{|c|}{$\mathrm{DV}=\log (1+$ Att_Cites $)$} \\
\hline & & NPubs & Frac_Pubs & alpha $(\mathrm{N})=1$ & $\begin{array}{c}\text { alpha }(\mathrm{N})=1 / \text { sqrt } \\
\mathrm{N})\end{array}$ & alpha $(\mathrm{N})=1 / \mathrm{N}$ \\
\hline & $(8-1)$ & $(8-2)$ & $(8-3)$ & $(8-4)$ & $(8-5)$ & $(8-6)$ \\
\hline Department-Year FE & Yes & Yes & Yes & Yes & Yes & Yes \\
\hline Scientist FE & Yes & Yes & Yes & Yes & Yes & Yes \\
\hline Career Stage FE & Yes & Yes & Yes & Yes & Yes & Yes \\
\hline \multirow[t]{2}{*}{ \# PIs from the same department } & 0.104 & -0.0421 & $-0.323 * * *$ & 0.0488 & $-0.214 * *$ & $-0.465^{* * *}$ \\
\hline & -0.1 & -0.03 & -0.03 & -0.11 & -0.1 & -0.1 \\
\hline \multirow[t]{2}{*}{ \# PIs from a different department } & $0.281 * * *$ & 0.000757 & $-0.273^{* * *}$ & $0.282 * *$ & 0.0175 & $-0.230 * *$ \\
\hline & -0.0978 & -0.0258 & -0.025 & -0.112 & -0.107 & -0.104 \\
\hline \multirow[t]{2}{*}{ \# non-PIs } & $0.116^{* * *}$ & 0.000517 & 0.0012 & $0.116^{* * *}$ & $0.116^{* * *}$ & $0.115^{* * *}$ \\
\hline & -0.03 & -0.01 & -0.01 & -0.04 & -0.04 & -0.04 \\
\hline \multirow[t]{2}{*}{ Constant } & $1.706 * * *$ & $0.750 * * *$ & $0.749 * * *$ & $1.767 * * *$ & $1.792 * * *$ & $1.819^{* * *}$ \\
\hline & -0.22 & -0.07 & -0.07 & -0.26 & -0.26 & -0.25 \\
\hline Observations & 2273 & 2273 & 2273 & 2273 & 2273 & 2273 \\
\hline R-squared & 0.246 & 0.18 & 0.274 & 0.222 & 0.223 & 0.234 \\
\hline
\end{tabular}

OLS; Robust standard errors in parentheses are clustered at the level of the individual MIT scientist

Significance level: *** $\mathrm{p}<0.01,{ }^{* *} \mathrm{p}<0.05,{ }^{*} \mathrm{p}<0.1$ 
TABLE 9: MECHANISM -- THE EFFECT OF PI COLLABORATION WITH DIFFERENT PIS (within MIT only)

\begin{tabular}{|c|c|c|c|c|c|c|}
\hline & QUALITY & \multicolumn{2}{|c|}{ QUANTITY } & \multicolumn{3}{|c|}{ CREDIT } \\
\hline & $\begin{array}{c}\mathrm{DV}=\log (1+ \\
\text { Cites by }\end{array}$ & \multicolumn{2}{|c|}{$\mathrm{DV}=\log (1+P u b s)$} & \multicolumn{3}{|c|}{$\mathrm{DV}=\log (1+$ Att_Cites $)$} \\
\hline & & NPubs & Frac_Pubs & $\operatorname{alpha}(\mathrm{N})=1$ & alpha $(\mathrm{N})=1 / \mathrm{sqrt}(\mathrm{N})$ & alpha $(\mathrm{N})=1 / \mathrm{N}$ \\
\hline & $(9-1)$ & $(9-2)$ & $(9-3)$ & $(9-4)$ & $(9-5)$ & $(9-6)$ \\
\hline $\begin{array}{l}\text { Department- } \\
\text { Year FE }\end{array}$ & Yes & Yes & Yes & Yes & Yes & Yes \\
\hline Scientist FE & Yes & Yes & Yes & Yes & Yes & Yes \\
\hline Career Stage FE & Yes & Yes & Yes & Yes & Yes & Yes \\
\hline \multicolumn{7}{|c|}{ Within Department Collaboration } \\
\hline \multirow[t]{2}{*}{ Junior PI } & 0.18 & -0.02 & $-0.293 * * *$ & 0.14 & -0.12 & $-0.378^{*}$ \\
\hline & $(0.18)$ & $(0.04)$ & $(0.05)$ & $(0.21)$ & $(0.20)$ & $(0.20)$ \\
\hline \multirow[t]{2}{*}{ Same rank PI } & 0.14 & $-0.0726^{*}$ & $-0.325 * * *$ & 0.06 & -0.18 & $-0.399 * * *$ \\
\hline & $(0.13)$ & $(0.04)$ & $(0.04)$ & $(0.14)$ & $(0.13)$ & $(0.13)$ \\
\hline \multirow[t]{2}{*}{ Senior PI } & -0.19 & 0 & $-0.234 * * *$ & -0.2 & $-0.411 *$ & $-0.612 * * *$ \\
\hline & $(0.20)$ & $(0.06)$ & $(0.06)$ & $(0.23)$ & $(0.22)$ & $(0.21)$ \\
\hline \multicolumn{7}{|c|}{ Across Department Collaboration } \\
\hline \multirow[t]{2}{*}{ Junior PI } & 0.704 & 0.187 & -0.0639 & $0.996^{* *}$ & 0.737 & 0.502 \\
\hline & $(0.47)$ & $(0.12)$ & $(0.12)$ & $(0.50)$ & $(0.48)$ & $(0.45)$ \\
\hline \multirow[t]{2}{*}{ Same rank PI } & $0.671 * * *$ & 0.037 & $-0.252 * * *$ & $0.733 * *$ & 0.44 & 0.162 \\
\hline & $(0.26)$ & $(0.07)$ & $(0.06)$ & $(0.30)$ & $(0.29)$ & $(0.29)$ \\
\hline \multirow[t]{2}{*}{ Senior PI } & -0.0428 & -0.00984 & $-0.232 * * *$ & -0.0776 & -0.341 & -0.58 \\
\hline & $(0.39)$ & $(0.08)$ & $(0.08)$ & $(0.42)$ & $(0.42)$ & $(0.42)$ \\
\hline \multirow[t]{2}{*}{ \# non-PIs } & $0.125^{* * *}$ & -0.0000413 & -0.00772 & $0.125 * * *$ & $0.116^{* * *}$ & $0.108 * * *$ \\
\hline & $(0.03)$ & $(0.01)$ & $(0.01)$ & $(0.04)$ & $(0.04)$ & $(0.03)$ \\
\hline \multirow[t]{2}{*}{ Constant } & $1.825^{* * *}$ & $0.739 * * *$ & $0.721 * * *$ & $1.861 * * *$ & $1.881 * * *$ & $1.903 * * *$ \\
\hline & $(0.22)$ & $(0.09)$ & $(0.08)$ & $(0.29)$ & $(0.28)$ & $(0.27)$ \\
\hline Observations & 2273 & 2273 & 2273 & 2273 & 2273 & 2273 \\
\hline R-squared & 0.248 & 0.182 & 0.239 & 0.225 & 0.227 & 0.234 \\
\hline
\end{tabular}

OLS; Robust standard errors in parentheses are clustered at the level of the individual MIT scientist

Significance level: *** $\mathrm{p}<0.01, * * \mathrm{p}<0.05, * \mathrm{p}<0.1$ 
FIGURE 1: DISTRIBUTION OF GROUP SIZES BY FACULTY-YEARS (DESCRIPTIVE STATISTICS)

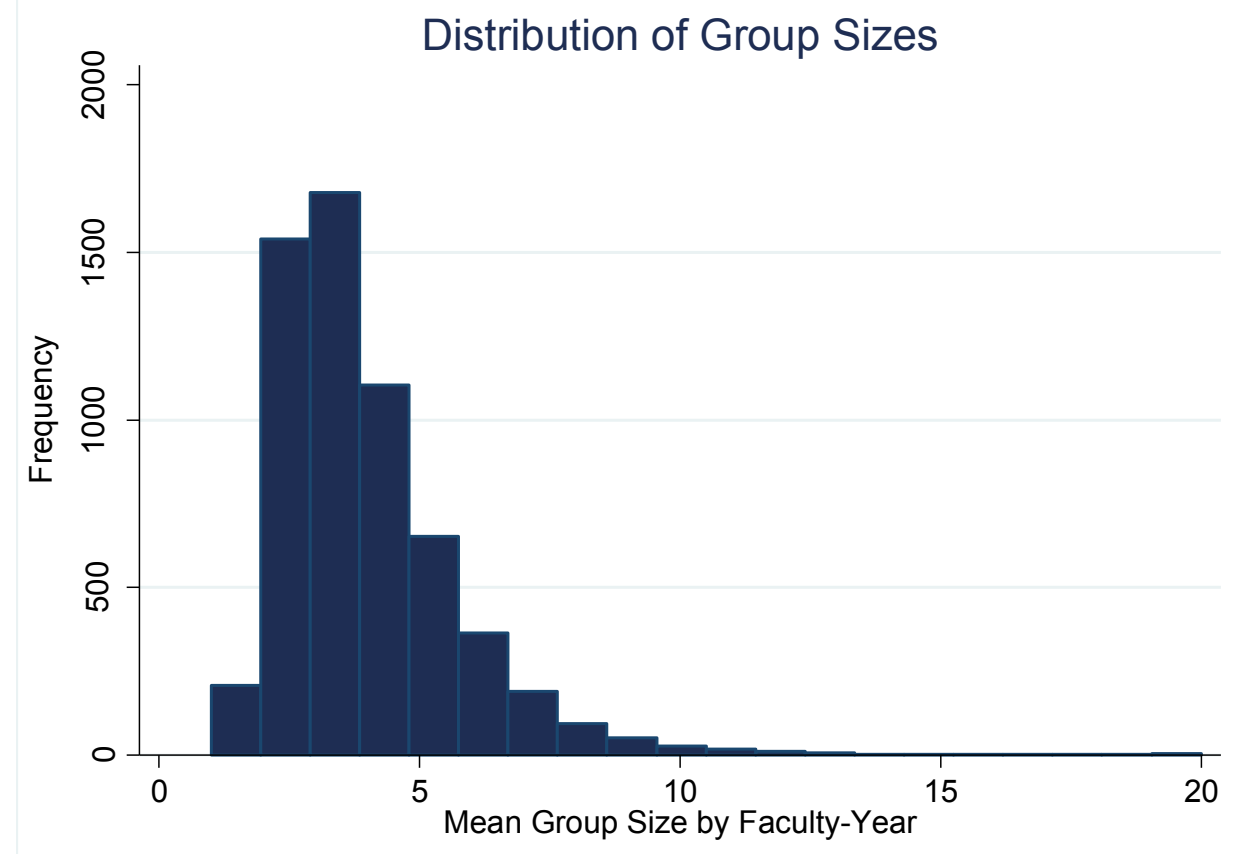




\section{FIGURE 2: RELATIONSHIP BETWEEN COLLABORATION, QUALITY, QUANTITY AND OVERALL YEARLY CITATIONS (ESTIMATES)}
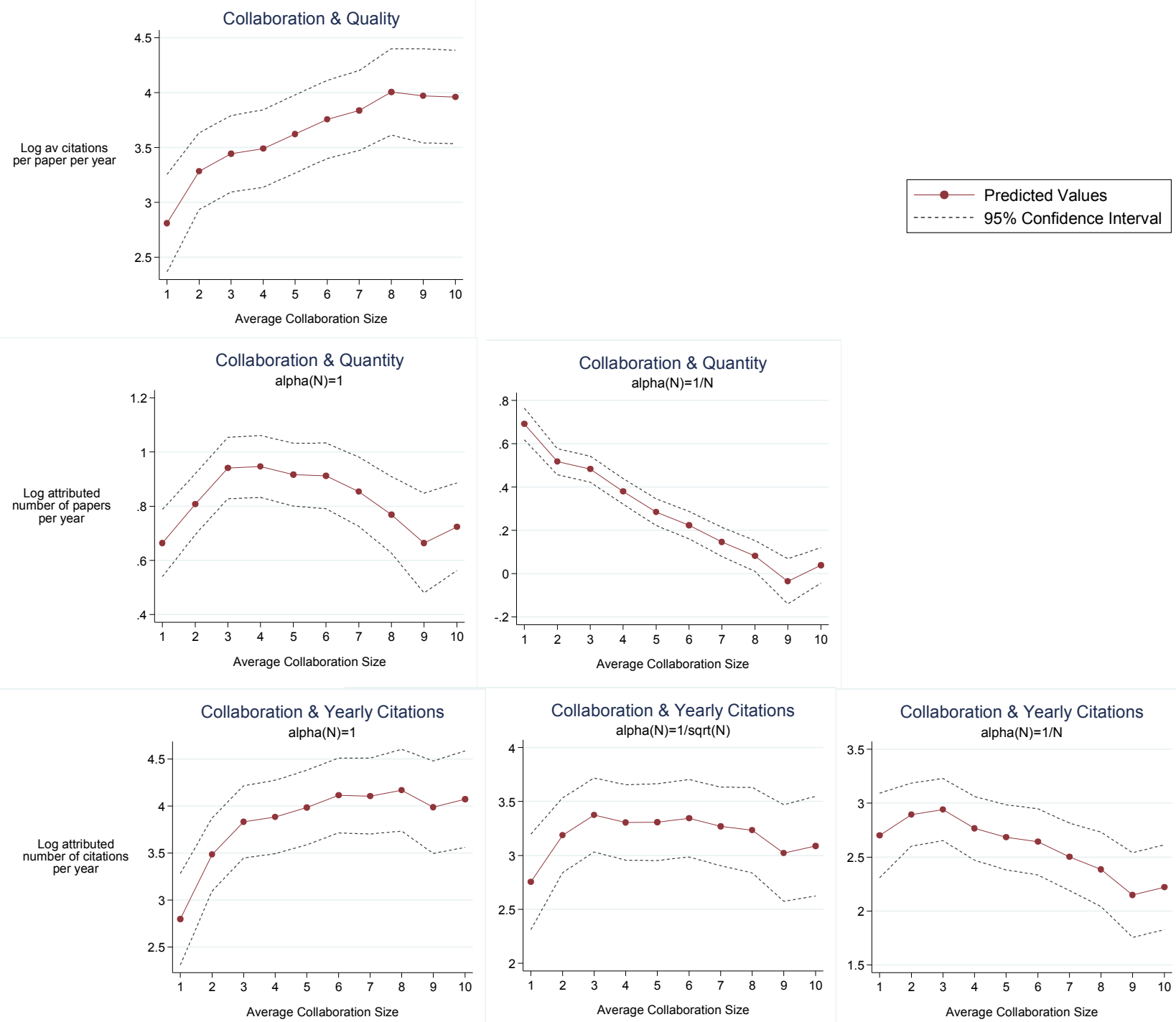

Note: These graphs show the results from Table 3 regressions where "Group Size" was turned into a series of indicator variables. X=1 on the graphs means that the average group size for the year was between 1 (included) and 2 (excluded). In the regressions, Group Size superior or equal to 11 was used as omitted category. For each regression, a Wald test rejected the null hypothesis that all 10 coefficients were equal. F-statistic results were respectively: "Collaboration \& Quality": $\mathrm{F}(9,660)=11.43$; "Collaboration \& Quantity" (alpha( $\mathrm{N})=1)$ : $\mathrm{F}(9,660)=13.19$;

"Collaboration \& Quantity" (alpha(N)=1/N): $\mathrm{F}(9,660)=64.92$; "Collaboration \& Yearly Citations" (alpha( $\mathrm{N})=1)$ : $\mathrm{F}(9,660)=11.09$; "Collaboration \& Yearly Citations" $($ alpha( $(\mathrm{N})=1 / \mathrm{sqrt}(\mathrm{N}))): \mathrm{F}(9,660)=3.46$; "Collaboration \& Yearly Citations" $($ alpha( $\mathrm{N})=1 / \mathrm{N}): \mathrm{F}(9,660)=8.76$ 